Article

\title{
Innovative Method for Longer Effective Corrosion Inhibition Time: Controlled Release Oil Palm Empty Fruit Bunch Hemicellulose Inhibitor Tablet
}

\author{
Nur Izzah Nabilah Haris ${ }^{1}\left(\mathbb{D}\right.$, Shafreeza Sobri ${ }^{1,2, *}$, Yus Aniza Yusof ${ }^{3}\left(\mathbb{D}\right.$ and Nur Kartinee Kassim ${ }^{4}$ \\ 1 Institute of Advanced Technology, Universiti Putra Malaysia, Selangor 43400, Malaysia; \\ nurizzahnabilah.haris@gmail.com \\ 2 Department of Chemical and Environmental Engineering, Faculty of Engineering, Universiti Putra Malaysia, \\ Selangor 43400, Malaysia \\ 3 Department of Process and Food Engineering, Faculty of Engineering, Universiti Putra Malaysia, \\ Selangor 43400, Malaysia; yus.aniza@upm.edu.my \\ 4 Department of Chemistry, Faculty of Science, Universiti Putra Malaysia, Selangor 43400, Malaysia; \\ kartinee@upm.edu.my \\ * Correspondence: shafreeza@upm.edu.my; Tel.: +60-397694456
}

Citation: Haris, N.I.N.; Sobri, S.; Yusof, Y.A.; Kassim, N.K. Innovative Method for Longer Effective Corrosion Inhibition Time: Controlled Release Oil Palm Empty Fruit Bunch Hemicellulose Inhibitor Tablet. Materials 2021, 14, 5657. https://doi.org/10.3390/ma14195657

Academic Editor: X. Ramón Nóvoa

Received: 30 August 2021

Accepted: 22 September 2021

Published: 28 September 2021

Publisher's Note: MDPI stays neutral with regard to jurisdictional claims in published maps and institutional affiliations.

Copyright: (c) 2021 by the authors. Licensee MDPI, Basel, Switzerland. This article is an open access article distributed under the terms and conditions of the Creative Commons Attribution (CC BY) license (https:// creativecommons.org/licenses/by/ $4.0 /)$.

\begin{abstract}
This study aims to develop a controlled release oil palm empty fruit bunch hemicellulose (EFB-H) inhibitor tablet for mild steel in $1 \mathrm{M} \mathrm{HCl}$. As plant extracts tend to deteriorate at longer immersion time, limiting its industrial applicability, we attempted to lengthen the inhibition time by forming a controlled release inhibitor tablet. Electrochemical methods (potentiodynamic polarization (PDP) and electrochemical impedance spectroscopy (EIS)) were employed to investigate the efficiency and mechanism of the inhibition. An optimum dosage and immersion time was determined via Response Surface Methodology (RSM). EFB-H tablet was formulated using D-optimal mixture design, and its anticorrosion action at extended immersion time was compared with EFB-H powder. PDP measurement revealed that EFB-H is a mixed type inhibitor. RSM optimization unveiled that the optimum point for a maximum inhibition efficiency (87.11\%) was at $0.33 \mathrm{~g}$ of EFB-H and $120 \mathrm{~h}$ of immersion time. Tablet T3 with EFB-H to gum Arabic to hydroxypropyl methylcellulose ratio of 66:0:34 portrayed the best tensile strength $(0.243 \mathrm{MPa})$, disintegration time (152 $\mathrm{min}$ ) and dissolution behavior. EFB-H tablet exhibited a longer-lasting inhibition effect than powder, which was $360 \mathrm{~h}$ as compared to $120 \mathrm{~h}$ for powder. Overall, EFB-H tablet has been successfully developed, and its enhanced effective inhibition time has been experimentally proven.
\end{abstract}

Keywords: controlled release tablet; corrosion inhibitors; weight loss; electrochemical test

\section{Introduction}

Corrosion inhibitors are substances that can minimize or eliminate metal corrosion once added to a corrosive solution. It is probably the most straightforward, inexpensive and efficacious strategy employed on a reasonably regular basis in the industrial sector [1]. Traditional inorganic inhibitors such as chromates, nitrates, tungstates and molybdates offer the best corrosion inhibition capability but they possess several shortcomings. A great majority of inorganic inhibitors possess toxicological issue, and thus the use of some inorganic inhibitors is now restricted, except in certain situations when human safety is on the line, such as in the aeronautical industry [2]. In addition, inorganic inhibitors are highly water soluble and do not work well in highly acidic solutions as they cannot be adsorbed on the metal surface. Furthermore, the presence of inorganic inhibitors in corrosive solutions will generate toxic gases as the metal starts to corrode [3]. Accordingly, despite the inorganic inhibitors being unarguably potent in inhibiting corrosion, environmentally friendly organic inhibitors should be explored. 
Plants-based inhibitors, particularly those that are biomass-based, have emerged as potential alternatives to conventional inhibitors. To date, numerous works have attempted to utilize plant products to mitigate the corrosion of steel in various media. Gouamid et al. [4] reported that date palm leaves hemicellulose at $500 \mathrm{ppm}$ achieved $89.25 \%$ inhibition efficiency for mild steel in $\mathrm{H}_{2} \mathrm{SO}_{4}$ solution. A study by Guedes et al. [5] has demonstrated that coconut husk extract at $1.2 \mathrm{gL}^{-1}$ could inhibit approximately $90 \%$ of carbon steel corrosion in a neutral water solution. Komalasari et al. [6] investigated the use of tea and coffee leaves extracts as inhibitors for carbon steel corrosion in $\mathrm{HCl}$ solution. The findings revealed that $1.5 \mathrm{gL}^{-1}$ of tea leaves extract and $1.5 \mathrm{gL}^{-1}$ of coffee leaves extract resulted in the highest inhibition efficiencies of $79 \%$ and $52 \%$, respectively. A recent study by Lima and co-authors [7] obtained $85.2 \%$ of inhibition efficiency with $0.8 \mathrm{gL}^{-1}$ of aqueous soybean extract for mild steel in $\mathrm{H}_{2} \mathrm{SO}_{4}$ solution. El-Hashemy et al. [8] reported that $500 \mathrm{ppm}$ of Calendula officinalis flower heads extract can inhibit up to $94.88 \%$ of mild steel corrosion in $\mathrm{HCl}$ medium. According to these reports, the capability of natural inhibitor to mitigate corrosion is undeniable.

Upon having a proper inhibitor source, there is still uncertainty whether the inhibitor is suitable for industrial application. This is due to the biodegradability of natural inhibitors, which causes their performances to deteriorate at longer immersion time, especially after $120 \mathrm{~h}$ of usage [9-11]. Even though degradation is a positive feature from an environmental point of view, it is a huge drawback for implementing natural inhibitors in the industry. Several studies have tested incorporating plant-based inhibitors in polymer coatings, which can extend the shelf life of the inhibitor $[12,13]$. However, this solution only applies to metal parts that can be coated. The industrial applicability of plant-based inhibitors for non-coated metal hitherto remains unresolved. A proposed solution to address this matter is to develop a controlled release inhibitor tablet. This idea was triggered based on the concept of pharmaceutical controlled release tablets and a patented invention of controlled release tablet for wastewater treatment. A controlled release inhibitor tablet is capable of releasing active compounds in a sustained manner, preventing the active compounds from degrading when in contact with corrosive environment, and hence extending the shelf life upon usage. Surprisingly, the use of controlled release tablets to combat plant-based inhibitors' degradation issue has not been closely examined. Based on the literature, only one patented and commercialized invention focused on applying controlled release tablets in the corrosion field. The invention provided tablet formulations composed of biofilm dispersant, scale inhibitor, biocide, inorganic corrosion inhibitor and polymers for treating industrial water systems [14]. The resulting $70 \mathrm{~mm}$ diameter tablet was reported to have a controlled release span of up to 6 months, which successfully omitted the requirement of daily dosing in the water treatment system, eliminated liquid chemical pump usage, reduced labor, operation and maintenance cost, and provided a safer working environment.

Oil palm empty fruit bunch (OPEFB) is a fibrous material from the empty stalks of fresh fruit bunches. Conventional oil palm milling involves five primary operations: fruit sterilization, fruit loosening/stripping, fruit digestion, oil extraction and oil clarification [15]. The oil palm fruits are removed from the fresh fruit bunches during the fruit stripping process, leaving EFB as a waste product. EFB is categorized as lignocellulosic biomass as it composed of cellulose, hemicellulose and lignin. As with other plant materials, OPEFB constitutes various components that can be categorized into several groups: structural components, extractive compounds, inorganic compounds (ash) and moisture. The structural make up of OPEFB cell walls, lignocellulose, consists of a complex matrix of cellulose, hemicellulose and lignin. In our previous study, we have discovered the outstanding performances of OPEFB raw fiber and extract as corrosion inhibitor for mild steel in acidic solution, which was primarily due to the existence of various chemical moieties in its structure [16,17].

The present work aims to develop a controlled release OPEFB hemicellulose (EFB-H) inhibitor tablet for mild steel in $1 \mathrm{M} \mathrm{HCl}$. The specific objectives targeted to achieve this goal are as follows: 
1. To characterize the functional groups and chemical constituents of EFB-H.

2. To investigate the mechanism and kinetics of EFB-H anticorrosion action using potentiodynamic polarization (PDP) and electrochemical impedance spectroscopy (EIS).

3. To optimize the inhibition efficiency of EFB-H using response surface methodologycentral composite design (RSM/CCD) at different dosages and immersion times.

4. To formulate EFB-H tablet using D-optimal mixture design, determine the tablet properties and compare its anticorrosion action with EFB-H powder inhibitor at extended immersion times.

\section{Materials and Methods}

\subsection{Materials}

The OPEFB used in this study was collected from Labu Palm Oil Mill located in Selangor, Malaysia. Chemical reagents such as $\mathrm{HCl}$, acetone and ethanol were supplied by R\&M Chemicals, Ever Gainful Enterprise Sdn. Bhd. (Selangor, Malaysia). Mild steel specimen with a chemical composition given in Table 1 were purchased from WGS Steel Sdn. Bhd. (Selangor, Malaysia).

Table 1. Chemical composition of mild steel.

\begin{tabular}{cc}
\hline Element & Chemical Composition (wt.\%) \\
\hline Iron & 98.874 \\
Carbon & 0.140 \\
Silicon & 0.170 \\
Manganese & 0.550 \\
Copper & 0.230 \\
Sulfur & 0.027 \\
Phosphorus & 0.009 \\
\hline
\end{tabular}

\subsection{Preparation of EFB-H Inhibitor}

The EFB-H was prepared in accordance to a typical mild acid hydrolysis method with minor adjustments [18-20]. The preparation began with soaking raw OPEFB in $300 \mathrm{~mL}$ of $1 \mathrm{M}$ $\mathrm{HCl}$ at a mass to volume ratio of 1:30. The mixture was stirred continuously at $100 \mathrm{rpm}$ and heated at a temperature of $90^{\circ} \mathrm{C}$ for $60 \mathrm{~min}$. The resulting mixture of solid and liquid was then cooled down to $40^{\circ} \mathrm{C}$ and filtered by vacuum filtration through a filter paper $(11 \mu \mathrm{m})$. The filtrate was precipitated by adding $500 \mathrm{~mL}$ of $95 \%$ ethanol, left for $24 \mathrm{~h}$ for complete precipitation and filtered again to recover the precipitate. The precipitate was then washed with ethanol and dried at $90^{\circ} \mathrm{C}$. Figure 1 depicts the general flow of EFB-H preparation.
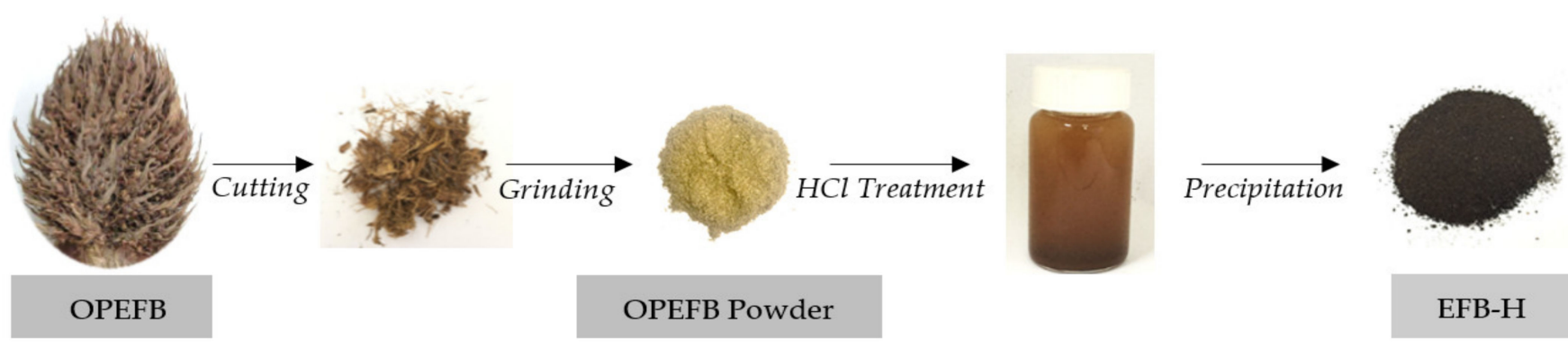

Figure 1. General flow of EFB-H preparation.

\subsection{Characterization of $E F B-H$}

2.3.1. Fourier-transform Infrared Spectroscopy Analysis

The FTIR analysis was performed using an FTIR spectrometer (Perkin Elmer, Spectrum 100, Waltham, MA, USA) equipped with an attenuated total reflectance (ATR) sampling accessory (Pike Technologies, Fitchburg, WI, USA). The crystal material used in the analysis 
was germanium (Ge). The EFB-H sample was scanned over the range of $4000 \mathrm{~cm}^{-1}$ to $650 \mathrm{~cm}^{-1}$ with a resolution of $4 \mathrm{~cm}^{-1}$.

\subsubsection{Chemical Composition (Cellulose, Hemicellulose, Lignin and Extractives)}

The chemical composition of EFB-H waste hydrolysate in terms of its cellulose, hemicellulose, lignin and extractives content was analyzed according to Technical Association of Pulp and Paper Industry (TAPPI) T222, TAPPI T249 and NREL TP-510-42619 standard procedures [21].

\subsection{Electrochemical Tests}

\subsubsection{Potentiodynamic Polarization}

All electrochemical tests were performed using an Autolab potentiostat (Metrohm, PGSTAT101, Herisau, Switzerland) equipped with Nova Software (Metrohm, Version 1.0, Herisau, Switzerland). The experimental set up of an electrochemical cell kit with a threeelectrode assembly is depicted in Figure 2. The working electrode is the mounted mild steel coupon with $0.79 \mathrm{~cm}^{2}$ of exposed surface area to the electrolyte. A platinum mesh was used as the counter electrode, while a standard $\mathrm{Ag} / \mathrm{AgCl}$ electrode was used as the reference electrode. The cell was filled with $300 \mathrm{~mL}$ of corrosive solution, $1 \mathrm{M} \mathrm{HCl}$ solution with and without the addition of EFB-H at varying dosages. After the electrochemical cell has been set up, the system was allowed to stabilize and reach a steady open circuit potential for $30 \mathrm{~min}[22,23]$. This step is crucial to ensure an accurate measurement as the corrosion reaction fluctuates at the initial stage [24]. After the system has stabilized, the potentiodynamic polarization measurement was performed with polarization sweep within $\pm 0.1 \mathrm{~V}$ of the open circuit potential at a scan rate of $1 \mathrm{mVs}^{-1}$ [25]. Each measurement was repeated three times, and only the average values were reported. New sets of corrosive solutions and mild steels were used for each repetition as the polarization measurement is a destructive technique that alters the electrode surface [26]. After completing the measurement, the data was plotted into a Tafel curve, and the electrochemical parameters such as the corrosion potential, Tafel slopes, corrosion current, corrosion rate and inhibition efficiency were computed. The corrosion potential can be computed from the lowest point of the current density in the Tafel plot, whereas the slope can be obtained by merely measuring the slope of each linear segment of the curve. As the corrosion current is known, the corrosion rate and the inhibition efficiency can be calculated using the following equations:

$$
\begin{gathered}
C_{R}=k \frac{i_{\text {corr }}}{d} E W \\
I E_{P D P}=\frac{i_{\text {corr }}-i_{\text {corr }}^{\text {inh }}}{i_{\text {corr }}} \times 100
\end{gathered}
$$

where $C_{R}$ is the corrosion rate, $k$ is a unit conversion factor (0.13), $d$ is the density of mild steel, $E W$ is the equivalent weight of iron, $I E_{P D P}$ is the inhibition efficiency derived from PDP method and $i_{\text {corr }}^{i n h}$ is the corrosion current density of inhibited system. 


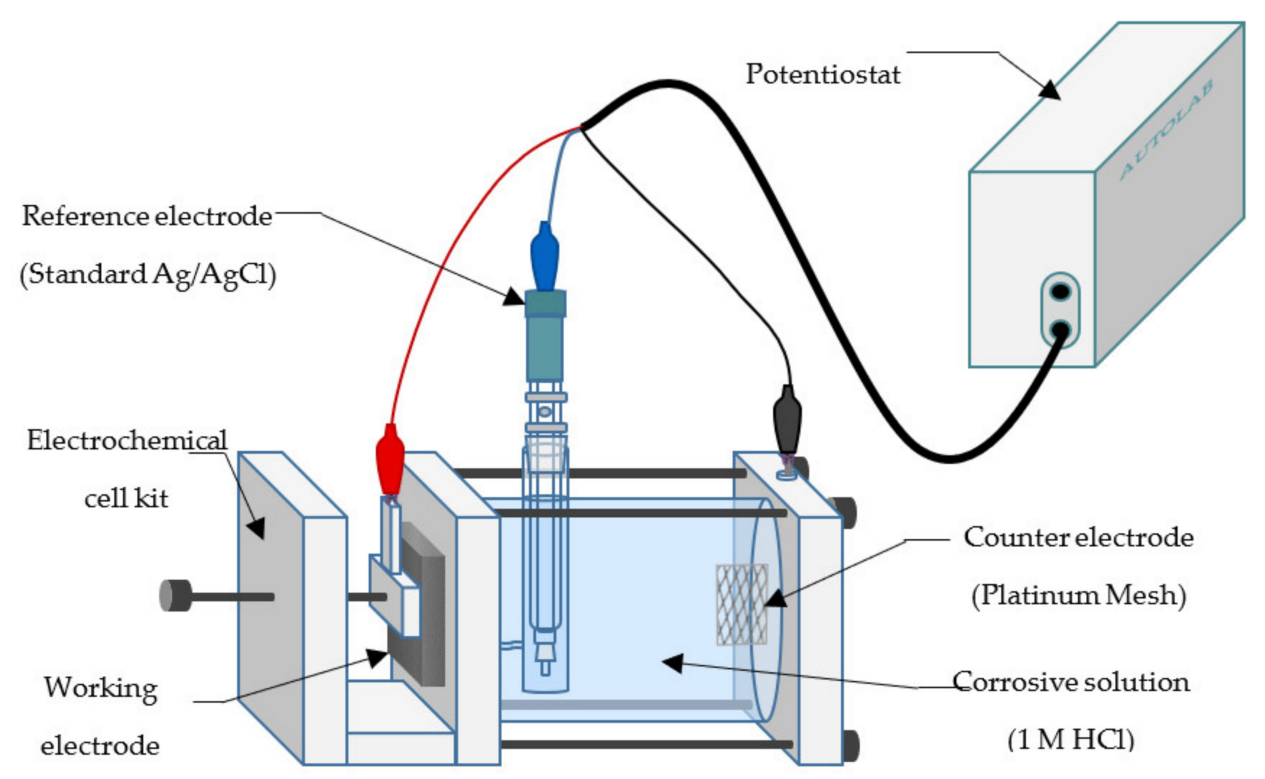

Figure 2. Schematic diagram of electrochemical test.

\subsubsection{Electrochemical Impedance Spectroscopy}

The EIS measurement was conducted using the same equipment, software and experimental set up as the PDP method. After reaching a steady-state, the EIS was performed within $100 \mathrm{kHz}$ to $100 \mathrm{mHz}$ of frequency and an amplitude of $10 \mathrm{mV}$ [27]. The measurements were repeated three times, and the average data was taken. The measured data was plotted into a Nyquist plot and fitted into an equivalent circuit. Ultimately, the parameters such as the charge transfer resistance, solution resistance, double layer capacitance and inhibition efficiency were calculated. The charge transfer resistance value was obtained from the Nyquist plot semicircle curve's diameter, while the solution resistance was measured graphically from the origin of the $\mathrm{x}$-axis to the initial point of the semicircle. The following equation is used to compute the double layer capacitance:

$$
C_{d l}=\frac{1}{\omega_{\max } R_{c t}}
$$

where $C_{d l}$ is the double layer capacitance, $\omega_{\max }$ is the frequency at which the real impedance is at a maximum (top of semicircle) and $R_{c t}$ is charge transfer resistance. Finally, the inhibition efficiency can be calculated using the following formula:

$$
I E_{E I S}=\frac{R_{c t}^{i n h}-R_{c t}}{R_{c t}^{i n h}} \times 100
$$

where $I E_{E I S}$ denotes the inhibition efficiency derived from EIS method and $R_{c t}$ and $R_{c t}^{i n h}$ are the charge transfer resistance for uninhibited and inhibited system, respectively.

\subsection{Optimization-Response Surface Methodology}

The RSM/CCD optimization was performed by Design Expert software (Stat-Ease Inc., Version 7.1, Minneapolis, MN, USA). Prior to designing an experiment, a preliminary study was conducted using one factor at a time (OFAT) method to identify suitable ranges of EFB-H dosage and immersion time. Two sets of OFAT-based experiments were performed:

1. Varying dosages of $0.1,0.3$ and $0.5 \mathrm{~g}$ at a fixed immersion time at $120 \mathrm{~h}$,

2. Varying immersion times of 24,120 and $216 \mathrm{~h}$ at a constant dosage.

All runs were conducted according to standard weight loss measurement method. Mild steel coupons were weighed to obtain the initial weight. Subsequently, each coupon 
was immersed in $300 \mathrm{~mL}$ of uninhibited and inhibited $1 \mathrm{M} \mathrm{HCl}$ solutions for $120 \mathrm{~h}$ at $25^{\circ} \mathrm{C}$. After immersion, each mild steel coupon was retrieved from the corrosive solution and rinsed using distilled water. Afterwards, the sample was air-dried to remove moisture and reweighed to acquire the final weight. Experiments were performed in triplicate, and average values were taken. The preliminary result was used to determine an appropriate range of variables with the highest possibility of finding an optimum response level. This step is important to avoid unnecessary experimental runs. The decided range was then specified in the software, and a set of experimental runs was generated [28]. Eventually, the software generated a mathematical expression representing the whole system within the variable ranges. The model was then used to predict an optimum level of EFB-H dosage and immersion time that yield the highest inhibition efficiency. Ultimately, the optimum point was validated experimentally to ensure the model's prediction's accuracy and validity.

\subsection{Preparation and Corrosion Inhibition Study of EFB-H Tablet}

\subsubsection{EFB-H Tablet Formulation-Mixture Design}

The EFB-H tablet was formulated with the aid of D-optimal design, Design Expert software (Stat-Ease Inc., Version 7.1, Minneapolis, MN, USA). Two polymers supplied by R\&M Chemicals, Ever Gainful Enterprise Sdn. Bhd. (Selangor, Malaysia), namely gum Arabic (GA) and hydroxypropyl methylcellulose (HPMC), were included in the formulation as binders to induce a controlled release behavior of the resulting tablet. The EFB-H powder weight was remained constant at an optimum level according to RSM optimization ( $0.33 \mathrm{~g})$, which is $66 \%$ on the basis of $0.5 \mathrm{~g}$ tablet total weight. In contrast, the ranges of GA and HPMC were varied from $0 \%$ to $34 \%$. These conditions were specified in the software, and a set of experimental design was generated. The tablets of varying formulations were prepared as described in the section that follows, and weight loss measurement was conducted at $120 \mathrm{~h}$ of immersion time with three replications. The formulation of selected tablets for further properties analysis are summarized in Table 2.

Table 2. Tablet formulation of T1, T2 and T3.

\begin{tabular}{cccc}
\hline \multirow{2}{*}{ Tablet } & \multicolumn{3}{c}{ Tablet Formulation $(\% w / w)$} \\
\cline { 2 - 4 } & EFB-H & GA & HPMC \\
\hline T1 & 100.0 & 0.0 & 0.0 \\
T2 & 66.0 & 34.0 & 0.0 \\
T3 & 66.0 & 0.0 & 34.0 \\
\hline
\end{tabular}

\subsubsection{EFB-H Tablet Compression}

The EFB-H tablet compression was conducted using a universal testing machine (Instron, 5566, Norwood, MA, USA) with a maximum allowable force of $10 \mathrm{kN}$ [29]. Firstly, mixtures of EFB-H, GA and HPMC powders were prepared, each at $0.5 \mathrm{~g}$ of total weight according to the designed formulation. The powders were thoroughly mixed and subsequently poured into a $13 \mathrm{~mm}$ uniaxial die (Specac, PT. No. 3000, Orpington, UK). Then, the die was compacted with $6 \mathrm{kN}$ of compression force at a compression speed of $1 \mathrm{~mm} \mathrm{~s}^{-1}$. Eventually, the tablet was ejected from the die and stored in a desiccator until further use. The compression process and the actual compressed tablet are illustrated in Figure 3. 

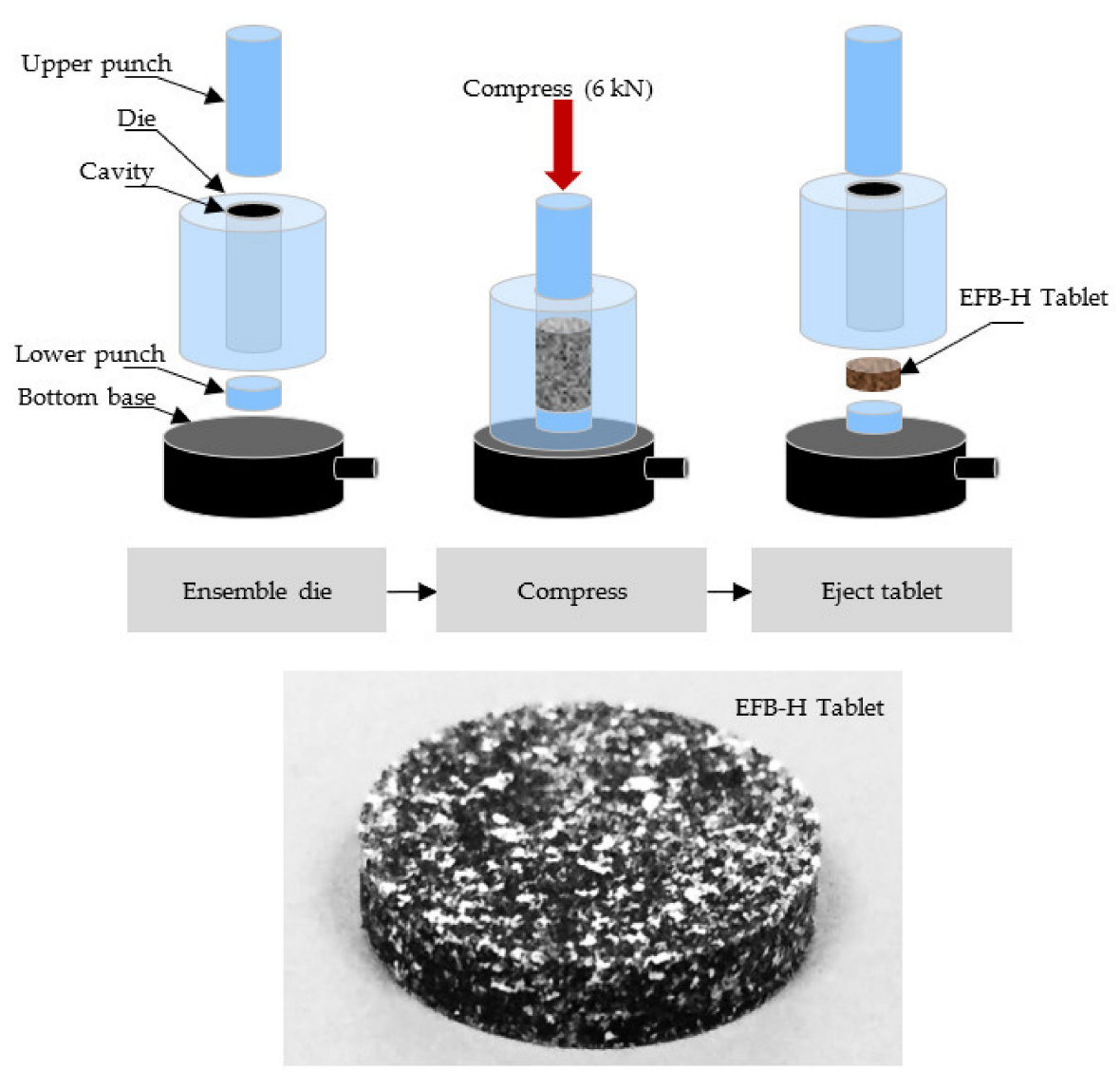

Figure 3. Schematic diagram of uniaxial die compression and compressed EFB-H tablet.

\subsubsection{Tablet Properties}

The tensile strength test of the EFB-H tablet was performed using a diametrical compression test using the same instrument used for tableting [29]. The test was conducted after $24 \mathrm{~h}$ of tablet compression to allow the tablet to achieve a stable-state. A tablet was placed between two flat plates of the instrument and compressed diametrically until it broke. The force upon breakage was recorded, and the tensile strength was calculated. The following equation is used to determine the tensile strength of a tablet;

$$
T=\frac{2 F}{\pi D T}
$$

where $T$ is the tensile strength, $F$ is the load at fracture, $D$ is the tablet diameter and $T$ is the tablet thickness.

The disintegration time of the tablet was determined using a jar test apparatus according to an established pharmaceutical method with some modifications to suit corrosion inhibition application [30]. $1 \mathrm{M} \mathrm{HCl}$ was used as the dissolution medium to represent actual corrosion application. An EFB-H tablet was placed in $500 \mathrm{~mL}$ of the dissolution medium and agitated at $100 \mathrm{rpm}$ at $25^{\circ} \mathrm{C}$. The time required for the tablet to dissolve completely was recorded.

The dissolution profile of EFB-H tablet was analyzed using a jar test apparatus, referring to a typical method for pharmaceutical tablets with some alterations to suit corrosion inhibition application [30]. Initially, a pre-weighed EFB-H tablet was placed in a mesh and positioned inside a beaker containing $500 \mathrm{~mL}$ of disintegration medium $(1 \mathrm{M} \mathrm{HCl})$. The solution was agitated at $100 \mathrm{rpm}$ and $25^{\circ} \mathrm{C}$. Every $10 \mathrm{~min}$ interval, the tablet was taken out from the beaker and dried by blotting tissue paper on the tablet's surface. The weight of the tablet was recorded and placed back into the vessel immediately. 
The dissolution profile was determined based on the erosion rate of the tablet. The erosion of the tablet was determined using the following expression;

$$
E=\frac{w_{0}-w_{1}}{w_{0}} \times 100
$$

where $E$ is the erosion, $w_{0}$ is the weight of tablet before immersion and $w_{1}$ is the weight of tablet after immersion at each interval.

\subsubsection{Extended Weight Loss Study}

The extended weight loss study for EFB-H tablet inhibitor was carried out according to the standard weight loss method described earlier at immersion times of 120, 240, 360, 480,600 and $720 \mathrm{~h}$.

\section{Results}

\subsection{EFB-H Characterization}

\subsubsection{Fourier-Transform Infrared Spectroscopy Analysis}

Figure 4 illustrates the FTIR spectrum of EFB-H. A strong and broad peak at $3352 \mathrm{~cm}^{-1}$ indicates $\mathrm{O}-\mathrm{H}$ stretching vibration in alcoholic and phenolic hydroxyl groups in cellulose, hemicellulose and lignin [31,32]. The absorption peak at $2930 \mathrm{~cm}^{-1}$ is due to C-H stretching of methyl and methylene groups in all components of lignocellulose, but most significant in cellulose [33,34]. The bands that appeared at $1720 \mathrm{~cm}^{-1}$ represents the vibration of hemicellulose's $\mathrm{C}=\mathrm{O}$ uronic and acetyl groups and/or hemicellulose's and lignin's ester linkage of the carboxyl and p-caumaric acid [35]. The band observed at $1650 \mathrm{~cm}^{-1}$ corresponds to O-H stretching due to adsorbed water [36-38]. The presence of $1620 \mathrm{~cm}^{-1}$ and $1510 \mathrm{~cm}^{-1}$ peaks is attributed to $C=C$ stretching of benzene ring in lignin structure [39-41]. The peaks located within 1315 to $1331 \mathrm{~cm}^{-1}$ are attributed to $\mathrm{C}-\mathrm{H}$ stretching from cellulose and hemicellulose [42]. The bands that appeared at 897 to $901 \mathrm{~cm}^{-1}$ are assigned as $\mathrm{C}-\mathrm{H}$ or $\mathrm{CH}_{2}$ bending vibrations, indicating the presence of $\beta$-glycosidic linkages; a bond that joins two different types of monosaccharides. This bond is a typical structure of cellulose and hemicellulose [43-45]. It is well known that these heteroatoms and functional groups contribute to excellent inhibitory properties [46,47].

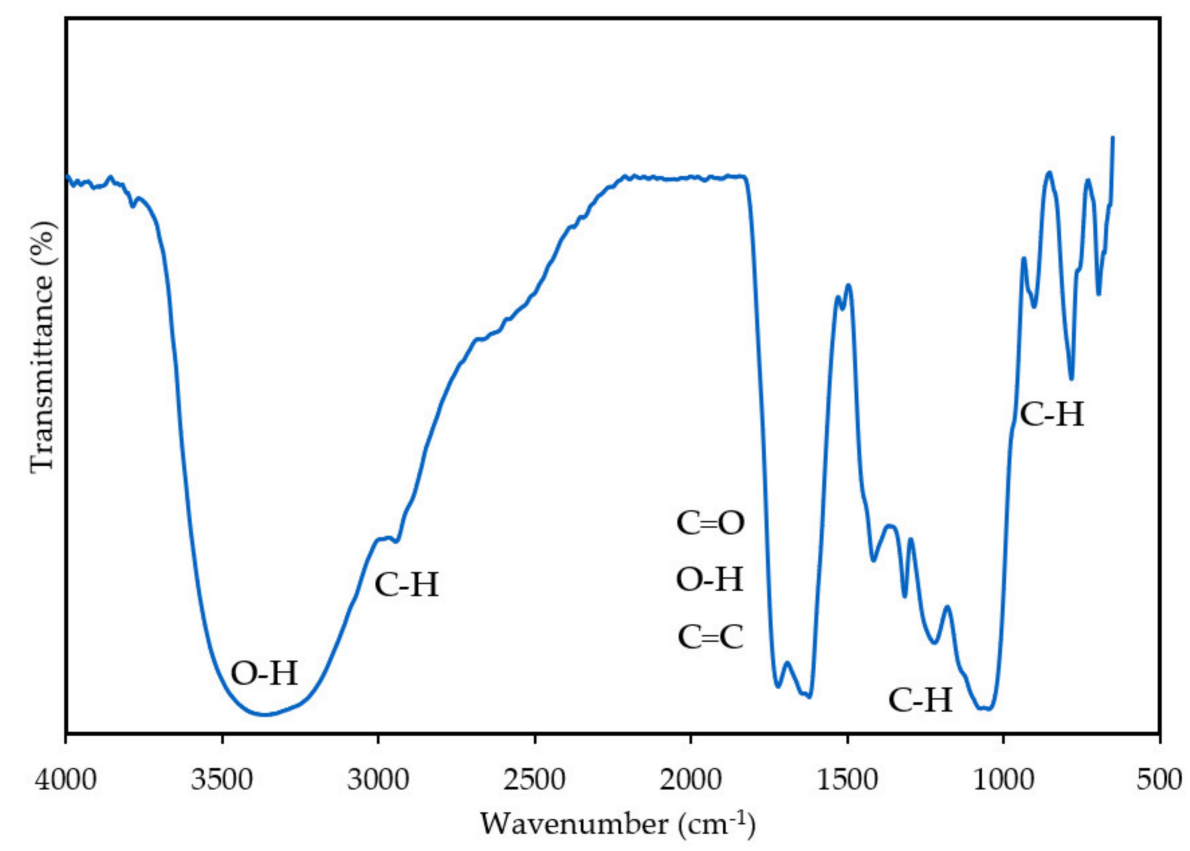

Figure 4. FTIR spectrum of EFB-H. 


\subsubsection{Chemical Composition (Cellulose, Hemicellulose, Lignin and Extractives)}

The structural compositions of raw OPEFB and EFB-H on weight bases are summarized in Table 3. Based on the data, it is obvious that the holocellulose in EFB-H was higher than the raw OPEFB. EFB-H predominantly composed of hemicellulose $(89.51 \%)$ and a minimal amount of cellulose $(0.85 \%)$. This finding revealed that the acid treatment had disrupted the holocellulose structure, particularly hemicellulose. The relatively high dissolution of hemicellulose compared to cellulose is attributable to its structure, amorphous properties, high polydiversity and low degree of polymerization [48]. In terms of lignin recovery, approximately more than half of the acid soluble and acid insoluble lignin was recovered from the raw OPEFB. Acid soluble lignin was present in EFB-H as the lignin fraction is soluble in acid solution. This type of lignin is also normally found in acid treated lignocellulosic materials [49]. Acid insoluble lignin's existence in a comparatively lower proportion is not unprecedented, as acid treatment also causes the breakdown and reorganization of the lignin structure [48]. In terms of the extractives, almost half of the amount extractives in the untreated sample were found in EFB-H. Extractives of plants are composed of various phytochemicals soluble in a wide range of polar and non-polar solvents [50]. Hence, compounds that are soluble in acid solution will technically present in EFB-H. Overall, it can be deduced that EFB-H is primarily composed of hemicellulose.

Table 3. Chemical compositions of raw OPEFB and EFB-H.

\begin{tabular}{ccc}
\hline \multirow{2}{*}{ Components } & \multicolumn{2}{c}{ Composition $(\%$ w/w) } \\
\cline { 2 - 3 } & Raw OPEFB & EFB-H \\
\hline Holocellulose & 83.56 & 90.34 \\
Cellulose & 29.85 & 0.85 \\
Hemicellulose & 53.71 & 89.51 \\
Lignin & 15.64 & 9.28 \\
Acid soluble & 8.78 & 5.39 \\
Acid insoluble & 6.86 & 3.89 \\
Extractives & 0.81 & 0.38 \\
\hline
\end{tabular}

\subsection{Electrochemical Tests}

\subsubsection{Potentiodynamic Polarization}

Potentiodynamic polarization (PDP) measurement was performed to unravel the kinetics of the electrochemical reaction of mild steel corrosion in the absence and presence of EFB-H. The Tafel polarization plot of mild steel at different dosages of inhibitor is depicted in Figure 5, whereas the kinetic parameters extracted from extrapolation of the plot such as the corrosion potential, Tafel slopes, corrosion current density, corrosion rate and inhibition efficiency are summarized in Table 4.

The corrosion potential is a valuable parameter to predict the corrosion damage in a system as well as to evaluate the effectiveness of a protective film. The corrosion potential of the mild steel specimen immersed in blank $1 \mathrm{M} \mathrm{HCl}$ solution relative to $\mathrm{Ag} / \mathrm{AgCl}$ reference electrode was found to be $-463.51 \mathrm{mV}$, which is within the range of $-450 \mathrm{mV}$ to $-465 \mathrm{mV}$ reported in previous studies with similar experimental conditions [51-53]. In the presence of EFB-H, the corrosion potentials had slightly increased by $42 \mathrm{mV}$ on average. Even though the change is minimal, it indicates that the inhibited system preferentially takes up electrons through reduction reaction than losing electrons via anodic reaction. In consequence, the dissolution of metal, which is governed by the anodic reaction is less likely to occur. 


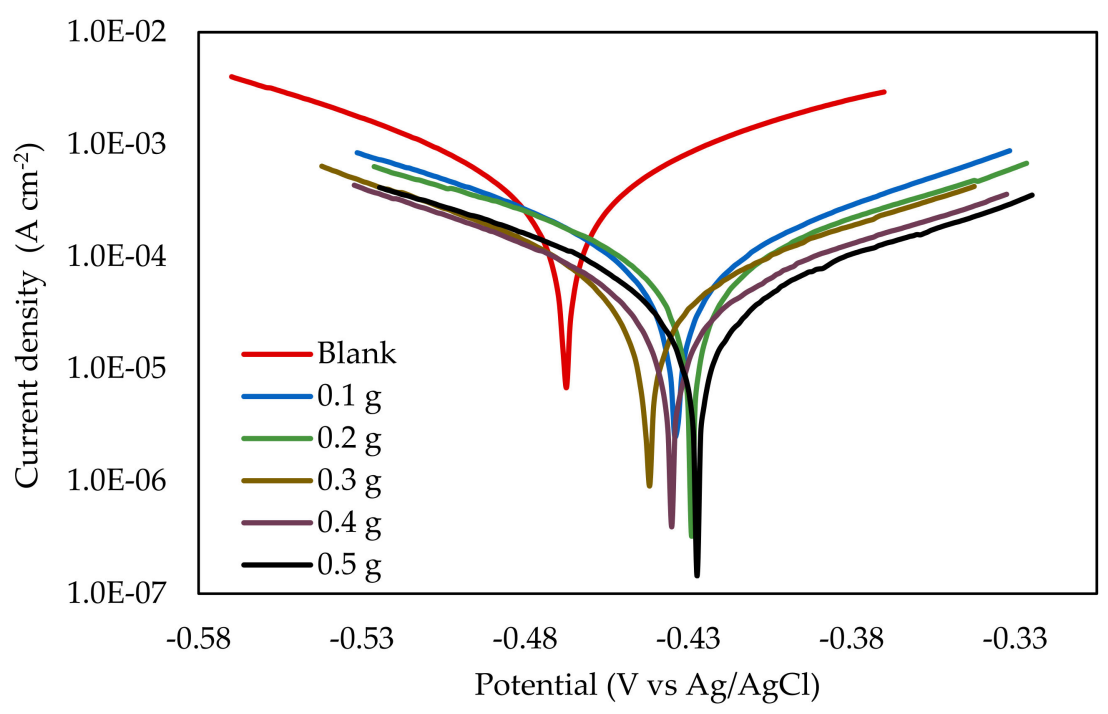

Figure 5. Potentiodynamic polarization curves of mild steel in $1 \mathrm{M} \mathrm{HCl}$ at different EFB-H dosages.

Table 4. Potentiodynamic polarization parameters of mild steel in $1 \mathrm{M} \mathrm{HCl}$ at different EFB-H concentrations.

\begin{tabular}{|c|c|c|c|c|c|c|}
\hline \multirow{2}{*}{$\begin{array}{l}\text { EFB-H Concentration } \\
\quad\left(\mathrm{g} \mathrm{s00} \mathrm{mL}^{-1}\right)\end{array}$} & \multirow{2}{*}{$\begin{array}{l}E_{\text {corr }} \\
(\mathrm{mV})\end{array}$} & $\beta_{a}$ & $-\beta_{c}$ & \multirow{2}{*}{$\begin{array}{c}I_{\text {corr }} \\
\left(\mu \mathrm{A} \mathrm{cm}^{-2}\right)\end{array}$} & \multirow{2}{*}{$\begin{array}{c}C_{R} \\
\left(\mathrm{~mm} \mathrm{y}^{-1}\right)\end{array}$} & \multirow{2}{*}{$I E_{P D P}(\%)$} \\
\hline & & \multicolumn{2}{|c|}{$\left(\mathrm{mVdecade}{ }^{-1}\right)$} & & & \\
\hline Blank & -463.51 & 122.14 & 135.25 & 598.65 & 8.79 & - \\
\hline 0.1 & -420.14 & 129.45 & 128.31 & 163.15 & 2.40 & 72.75 \\
\hline 0.2 & -418.84 & 136.97 & 145.08 & 128.28 & 1.88 & 78.57 \\
\hline 0.3 & -431.57 & 109.04 & 139.38 & 78.04 & 1.15 & 86.96 \\
\hline 0.4 & -421.95 & 109.59 & 133.09 & 58.52 & 0.86 & 90.22 \\
\hline 0.5 & -414.49 & 111.89 & 140.28 & 60.31 & 0.89 & 89.92 \\
\hline
\end{tabular}

Note: $E_{c o r r}$ is corrosion potential; $\beta_{a}$ is anodic Tafel slope; $\beta_{c}$ is cathodic Tafel slope; $I_{c o r r}$ is corrosion current density; $C_{R}$ is corrosion rate; $I E_{P D P}$ is inhibition efficiency from potentiodynamic polarization method.

The Tafel line is helpful to determine the type of inhibitor by observing the anodic and cathodic branches change with the incorporation of an inhibitor. Based on the data, the anodic and cathodic branches have shifted to lower current densities upon the addition of EFB-H. This trend suggests that EFB-H inhibits corrosion by retarding both reactions simultaneously [54]. Despite the slight increase of corrosion potentials by $42 \mathrm{mV}$, the inhibitor is considered as a mixed type inhibitor as the potential increase was lower than $85 \mathrm{mV}$ [55]. Accordingly, EFB-H is categorized as a mixed-type inhibitor similar to various other plant-based inhibitors such as tea extract and Asian arrowroot leaf extract [56,57]. Additionally, the anodic and cathodic branches' linearity indicates that both reactions are controlled by a charge transfer process [58].

With respect to the corrosion current density, the result revealed that the values reduced appreciably upon the increase of EFB-H dosage. The corrosion current density is related to the electrochemical reaction rate and can be easily determined experimentally by extrapolating the Tafel plot [59]. Lower corrosion current density is preferred upon addition of inhibitor as it indicates a lower corrosion rate. Based on the result, the reduction of current density and corrosion rate reflects that the inhibitor molecules were adsorbed on the mild steel surface and retarded the electrochemical reactions [60]. Hemicellulose components such as xylose, arabinose and glucose are among the inhibitor molecules adsorbed. Other molecules in EFB-H might as well be adsorbed on the surface; however, due to the low concentration, their contribution to the inhibition is not superior. The inhibition efficiency resembles the inhibitor's performance, which was calculated from the reduction of the current density. According to the result, it is evident that the inhibition efficiency increased with the increase of EFB-H dosage. This indicates that more inhibitor 
molecules are adsorbed at higher dosages, providing better surface coverage and better inhibition performance [60].

\subsubsection{Electrochemical Impedance Spectroscopy}

To procure a more detailed information on the corrosion inhibition mechanism of EFB-H on mild steel, EIS experiment was also performed. In the EIS method, impedance is used to relate theoretical circuit elements to the corrosion system [61]. The Nyquist plots of mild steel in the absence and presence of inhibitor are illustrated in Figure 6. Distinctly, the plots comprised of single capacitive loops, which suggests that the corrosion process is controlled by a charge-transfer process [62-64]. However, the capacitive loops curve slightly deviated from a perfect semicircle shape, especially at higher frequencies. In addition, the curves are also slightly depressed downwards instead of having perfectly round curvatures. These discrepancies are predominantly caused by the mild steel surface's heterogeneity and roughness, which is a typical condition of the corrosion system [27]. With respect to the capacitive loop diameter, the size of the uninhibited $1 \mathrm{M} \mathrm{HCl}$ was the smallest, and larger loops were obtained as the EFB-H dosage was increased from 0.1 to $0.5 \mathrm{~g}$. The diameter of the loop resembles the charge transfer resistance, $R_{c t}$. The larger diameter of the capacitive loops at higher inhibitor dosage implies higher resistance to corrosion due to more molecules' adsorption on the mild steel surface [27].

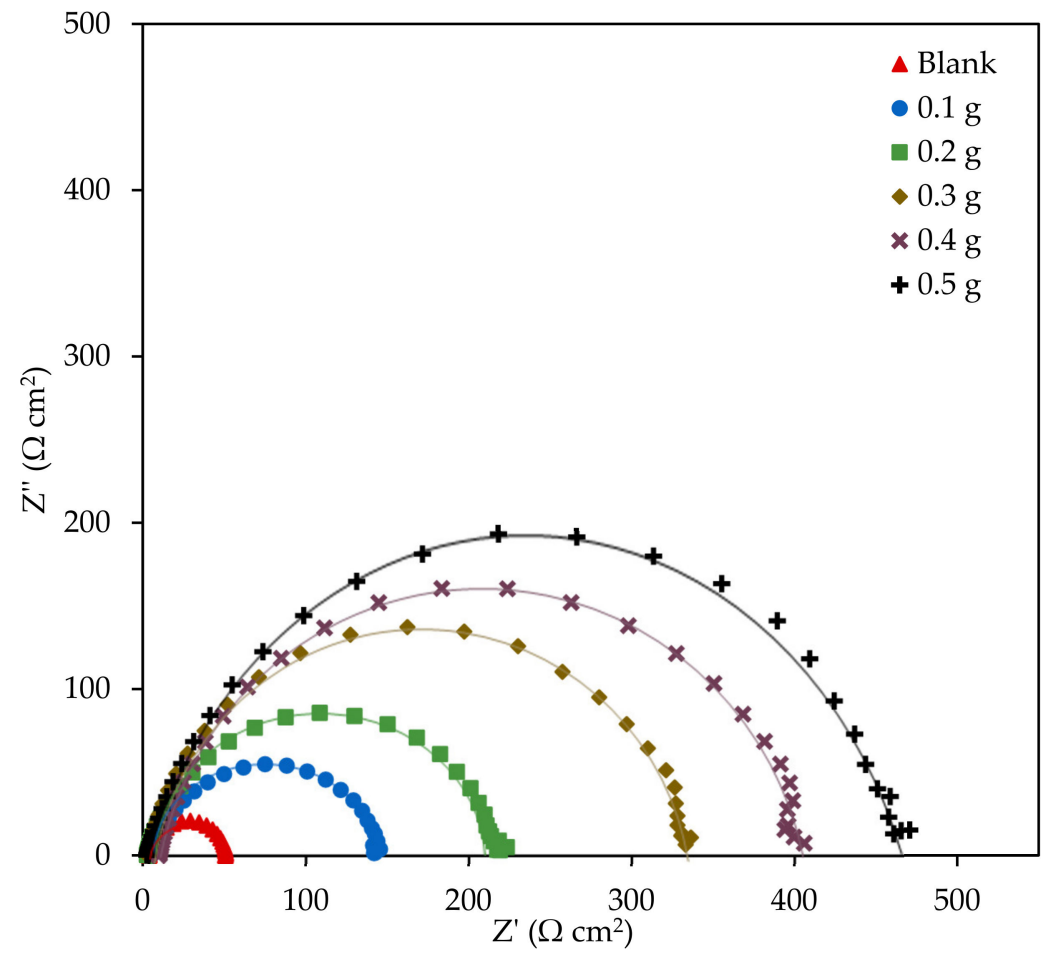

Figure 6. Nyquist plots of mild steel in $1 \mathrm{M} \mathrm{HCl}$ at different EFB-H dosages.

To further understand the electrochemical aspect of the corrosion inhibition, the results from EIS measurement were fitted to an equivalent circuit. Ideally, the most straightforward Nyquist plot with only one perfect semicircle can be simulated by Randles equivalent circuit, which assumes homogeneous and flawless metal surface that behaves as a pure capacitor. However, in reality, the metal surface is microscopically rough and heterogeneous even with extensive cleaning and polishing. Accordingly, a constant phase element (CPE) was employed instead of a pure capacitor to accurately resemble the data [65]. The electrochemical parameters such as the solution resistance, charge transfer resistance, factor of deviation due to metal roughness and double layer capacitance in addition to the inhibition efficiency are listed in Table 5. 
Table 5. Electrochemical impedance parameters of mild steel in $1 \mathrm{M} \mathrm{HCl}$ at different EFB-H concentrations.

\begin{tabular}{|c|c|c|c|c|c|}
\hline $\begin{array}{l}\text { EFB-H Concentration } \\
\quad\left(\mathrm{g} 300 \mathrm{~mL}^{-1}\right)\end{array}$ & $\begin{array}{c}R_{S} \\
\left(\Omega \mathrm{cm}^{2}\right)\end{array}$ & $\begin{array}{c}R_{c t} \\
\left(\Omega \mathrm{cm}^{2}\right)\end{array}$ & $\begin{array}{c}I E_{E I S} \\
(\%)\end{array}$ & $n$ & $\begin{array}{c}C_{d l} \\
\left(\mu \mathrm{F} \mathrm{cm}^{-2}\right)\end{array}$ \\
\hline Blank & 3.78 & 47.28 & - & 0.9987 & 145.36 \\
\hline 0.1 & 4.06 & 142.08 & 66.72 & 0.9971 & 93.20 \\
\hline 0.2 & 3.18 & 216.14 & 78.12 & 0.9975 & 83.56 \\
\hline 0.3 & 1.68 & 336.13 & 85.93 & 0.9978 & 72.81 \\
\hline 0.4 & 1.20 & 397.11 & 88.09 & 0.9978 & 69.07 \\
\hline 0.5 & 4.09 & 462.77 & 89.78 & 0.9979 & 72.86 \\
\hline
\end{tabular}

Note: $R_{S}$ is solution resistance; $R_{c t}$ is charge transfer resistance; $I E_{E I S}$ is inhibition efficiency from EIS method; $n$ is deviation factor; $C_{d l}$ is double layer capacitance.

In terms of the solution resistance, no obvious trend was observed in blank and inhibited solutions. Thus, it can be inferred that EFB-H do not alter the ionic conductivity of the solution. The charge transfer resistance resembles the metal-solution interface's resistance that prevents the movement of ions from the metal into the aqueous solution. As can be seen in the table, the charge transfer resistance increased by 3 folds from 47.28 to $142.08 \Omega \mathrm{cm}^{2}$ upon the addition of OPEFB waste hydrolysate at the lowest dosage. With successive increases in the inhibitor dosage, a substantial increment of resistance was observed as anticipated. By utilizing the reduction of charge transfer resistance, the inhibition efficiency of EFB-H can be calculated. The finding is in agreement with the inhibition efficiencies obtained by weight loss and polarization techniques, which demonstrated that inhibition efficiency improved with increasing inhibitor dosages.

The deviation factor ranging from 0 to 1 indicates the deviation of the actual situation from the ideal system. A value closer to 0 implies that the CPE behaves as a resistor, while a value closer to 1 suggests that the CPE acts similar to a capacitor, as proposed in Randles equivalent circuit [8]. Based on the data, the average deviation factor value was 0.998, which suggests that the mild steel corrosion in the presence and absence of EFB-H deviated by only $2 \%$ from the ideal circuit. The deviation observed in the study is far lower than those reported in the literature $[8,27,66,67]$. Hence it is possible to deduce that the mild steel surface inhomogeneity used in the study was not severe.

The double layer capacitance is a capacitance value associated with the double layer formed within the metal/electrolyte interface. Physically, the double layer capacitance exists in a corrosion system due to the charge distribution of ions and polar molecules such as water in the interface. According to the result, the highest capacitance of $145.36 \mu \mathrm{F} \mathrm{cm}^{-2}$ was observed in the blank solution, and appreciable capacitance reduction was observed as EFB-H was added into the solution. The decrease in capacitance value is typically caused by the reduction of the dielectric constant $(\varepsilon)$ and/or the thickening of the double layer. Organic compounds typically have lower dielectric constant values $(\varepsilon \approx 3-4)$ compared to water $(\varepsilon \approx 80)$, owing to their outstanding electrical insulating properties $[68,69]$. Since the molecules of EFB-H displace water molecules on the metal surface upon adsorption, the overall electric conductance drops, and thus restricting the electrical current flow through the double layer [62]. Furthermore, the adsorption of larger inhibitor molecules will also increase the double layer's thickness [70,71]. On that basis, it can be concluded that both aspects; namely the reduction of the dielectric constant and the thickening of the double layer, synergistically lowered the double layer capacitance and the corrosion reaction of the mild steel.

\subsection{Optimization-Response Surface Methodology}

An inhibitor's inhibition efficiency is immensely dependent on the inhibitor dosage and immersion time [72]. Hence, RSM/CCD optimization was performed to determine an optimum value of dosage and immersion time for maximum efficacy of EFB-H. Table 6 demonstrates the preliminary study result. It appeared that $0.3 \mathrm{~g}$ of EFB-H yielded the maximum inhibition efficiency, and higher dosages than $0.3 \mathrm{~g}$ had no significant influence on the inhibition efficiency. The optimum point of dosage at $120 \mathrm{~h}$ of immersion time 
possibly lied between 0.3 and $0.4 \mathrm{~g}$ of dosage. With respect to the immersion time, the efficiency improved as the immersion time was increased from 24 to $120 \mathrm{~h}$. However, the performance declined as the corrosion test was prolonged to $216 \mathrm{~h}$. The possible optimum point at $0.3 \mathrm{~g}$ of dosage was at $120 \mathrm{~h}$ of immersion time. Based on the findings, it can be deduced that the optimum point lies between the preliminary variables ranges; 0.1 to $0.5 \mathrm{~g}$ of EFB-H dosage and 24 to $216 \mathrm{~h}$ of immersion time. Hence this range would be appropriate for RSM optimization purpose.

Table 6. Inhibition efficiencies of mild steel in $1 \mathrm{M} \mathrm{HCl}$ at different EFB-H dosages and immersion times at $25^{\circ} \mathrm{C}$ using OFAT method.

\begin{tabular}{ccc}
\hline \multicolumn{2}{c}{ Independent Parameter } & \multirow{I}{*}{$\boldsymbol{I E}_{W L}(\mathbf{\%})$} \\
\cline { 1 - 2 } EFB-H Dosage (g) & Immersion Time (h) & \\
\hline 0.1 & & $80.37 \pm 0.72$ \\
0.3 & 120 & $85.66 \pm 1.28$ \\
0.5 & & $85.37 \pm 1.44$ \\
\hline & 24 & $66.35 \pm 0.69$ \\
& 120 & $85.66 \pm 1.28$ \\
& 216 & $66.69 \pm 1.43$ \\
\hline
\end{tabular}

Note: $I E_{W L}$ is inhibition efficiency from weight loss method. Values are mean \pm standard deviation.

After determining the appropriate range of variables, RSM/CCD was performed to achieve optimum parameters for maximum inhibition efficiency. A total of 13 runs were generated in the design matrix, as depicted in Table 7. The expression representing the influence of EFB-H dosage and immersion time towards the inhibition efficiency of mild steel in $1 \mathrm{M} \mathrm{HCl}$ at $25^{\circ} \mathrm{C}$ is given as follows:

$I E(\%)=44.98+55.82 A+0.50 B-5.73 \times 10^{-3} A B-69.44 A^{2}-2.08 \times 10^{-3} B^{2}$

where $I E$ is inhibition efficiency, $A$ is EFB-H dosage and $B$ is immersion time.

Table 7. CCD matrix of two variables (EFB-H dosage and immersion time) and one response (inhibition efficiency).

\begin{tabular}{ccccc}
\hline $\begin{array}{c}\text { Standard } \\
\text { Order }\end{array}$ & Run Order & EFB-H Dosage (g) & $\begin{array}{c}\text { Immersion } \\
\text { Time (h) }\end{array}$ & $\begin{array}{c}I E_{W L} \\
(\mathbf{\%})\end{array}$ \\
\hline 1 & 10 & 0.1 & 120.0 & 80.37 \\
2 & 4 & 0.5 & 120.0 & 85.00 \\
3 & 8 & 0.1 & 360.0 & 59.02 \\
4 & 6 & 0.5 & 360.0 & 77.61 \\
5 & 2 & 0.1 & 240.0 & 57.25 \\
6 & 11 & 0.5 & 240.0 & 66.55 \\
7 & 9 & 0.3 & 120.0 & 85.66 \\
8 & 1 & 0.3 & 360.0 & 77.41 \\
9 & 7 & 0.3 & 240.0 & 65.23 \\
10 & 13 & 0.3 & 240.0 & 67.89 \\
11 & 5 & 0.3 & 240.0 & 67.84 \\
12 & 3 & 0.3 & 240.0 & 66.49 \\
13 & 12 & 0.3 & 240.0 & 64.57 \\
\hline
\end{tabular}

Note: $I E_{W L}$ is inhibition efficiency from weight loss method.

Figure 7 depicts the response surface plot of EFB-H dosage and immersion time effects on the corrosion inhibition efficiency. It is evident that the inhibitor performance increased with increasing dosage from 0.1 to $0.3 \mathrm{~g}$. Further increment of dosage to $0.5 \mathrm{~g}$ had no substantial effect on the performance. With respect to the immersion time, extending the immersion time from 24 to $120 \mathrm{~h}$ had increased the performance. This finding broadly supports the studies of other inhibitors such as galactomannan ( 1 to $48 \mathrm{~h}$ ), benzimidazole derivative ( 24 to $72 \mathrm{~h}$ ), Schiff base molecule ( 2 to $96 \mathrm{~h}$ ) and carbon dots (6 to $120 \mathrm{~h}$ ) [73-76]. Contrarily, 
the effectiveness of EFB-H reduced significantly beyond $120 \mathrm{~h}$ of immersion time. The decline in inhibition efficiency is rarely reported in the literature, probably due to the short time range (less than $120 \mathrm{~h}$ ) used in the previous studies. Some studies had shown that the hydrolysis degradation of inhibitor molecules might occur during corrosion testing in acid solution [77]. Even though exhibiting a steep decline at prolonged immersion time, the EFB-H behaved excellently at $120 \mathrm{~h}$, which is comparatively longer than other inhibitors.

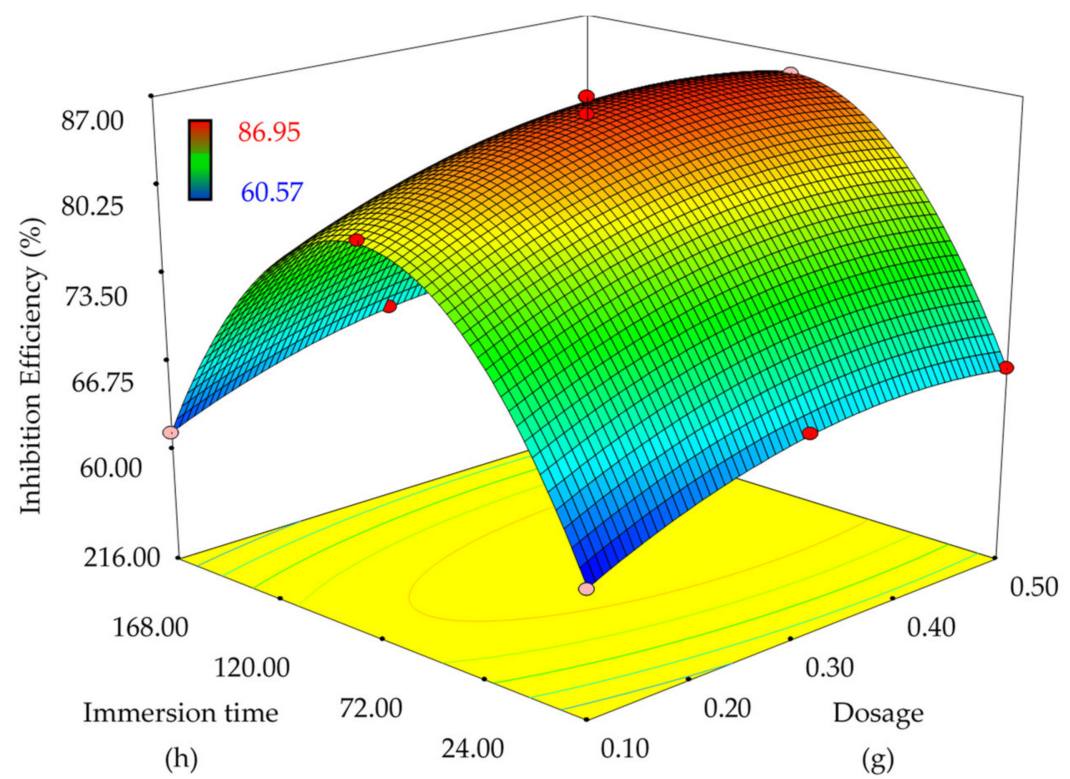

Figure 7. RSM surface plot; inhibition efficiencies of mild steel in $1 \mathrm{M} \mathrm{HCl}$ at different $\mathrm{EFB}-\mathrm{H}$ dosages and immersion times at $25^{\circ} \mathrm{C}$.

The final part addresses optimizing the parameters for maximum inhibition efficiency of EFB-H using the generated model. For this purpose, the response (inhibition efficiency) was set to "maximum" to achieve the highest possible value. Based on the specified condition, the maximum efficiency was predicted to be $85.95 \%$ at an inhibitor dosage of $0.33 \mathrm{~g}$ and an immersion time of $120 \mathrm{~h}$. A validation experiment at the optimum point revealed that the inhibition efficiency was $87.11 \pm 1.91 \%$, which proved that the model is accurate and reliable for prediction. Such a conclusion was made on the basis of a small error between the actual and the predicted value, which was only $1.35 \%$.

\subsection{Corrosion Inhibition Study of Oil Palm Empty Fruit Bunch Tablet Inhibitor}

\subsubsection{Mixture Design Formulation}

As discussed earlier, the effectiveness of EFB-H reduced after $120 \mathrm{~h}$ of immersion time, which is possibly caused by the desorption of inhibitor molecules and the hydrolysis degradation of inhibitor molecules in acid solution. In an attempt to prolong the effective duration of the inhibitor, a well-established concept in the pharmaceutical field, a sustained release tablet is applied herein as a proof of concept for enhancements in corrosion inhibition application. In addition, corrosion inhibitor tablets' application is industrially advantageous in the sense of ease of handling, eliminating the need for regular dosing and ensuring a safer working environment [14]. In this study, EFB-H tablets incorporated with a polymer matrix with a diameter of $13 \mathrm{~mm}$ and a weight of $0.5 \mathrm{~g}$ were fabricated. The tablets were composed of an active ingredient: EFB-H in powder form, as well as individual and mixtures of two polymer binders, GA and HPMC. The formulations and the respective corrosion inhibition efficiency responses are tabulated in Table 8. The composition of EFB-H and the immersion time was controlled at the optimum condition derived from RSM optimization, which are at $66 \%$ (0.33 g per $0.5 \mathrm{~g}$ tablet $)$ and $120 \mathrm{~h}$. 
Table 8. D-optimal mixture design matrix for two mixtures (GA and HPMC) and one response (inhibition efficiency).

\begin{tabular}{cccccc}
\hline Standard Order & Run Order & $\begin{array}{c}\text { EFB-H } \\
\mathbf{( \% )}\end{array}$ & $\begin{array}{c}\text { GA } \\
\mathbf{( \% )}\end{array}$ & $\begin{array}{c}\text { HPMC } \\
\mathbf{( \% )}\end{array}$ & $\begin{array}{c}\boldsymbol{I} \text { ( } E_{W L} \\
\mathbf{( \% )}\end{array}$ \\
\hline 1 & 1 & 66.00 & 34.00 & 0.00 & 81.90 \\
2 & 3 & 66.00 & 0.00 & 34.00 & 85.64 \\
3 & 7 & 66.00 & 17.34 & 16.66 & 80.79 \\
4 & 13 & 66.00 & 8.62 & 25.38 & 79.01 \\
5 & 11 & 66.00 & 25.62 & 8.38 & 77.67 \\
6 & 10 & 66.00 & 12.94 & 21.06 & 77.12 \\
7 & 6 & 66.00 & 4.29 & 29.71 & 79.92 \\
8 & 4 & 66.00 & 21.42 & 12.58 & 76.69 \\
9 & 5 & 66.00 & 34.00 & 0.00 & 81.07 \\
10 & 2 & 66.00 & 0.00 & 34.00 & 84.02 \\
11 & 9 & 66.00 & 34.00 & 0.00 & 80.57 \\
12 & 12 & 66.00 & 0.00 & 34.00 & 83.23 \\
13 & 8 & 66.00 & 34.00 & 0.00 & 81.49 \\
\hline
\end{tabular}

Note: $I E_{W L}$ is inhibition efficiency from weight loss method.

The expression representing the effect of GA and HPMC composition towards the inhibition efficiency EFB-H tablet for mild steel in $1 \mathrm{M} \mathrm{HCl}$ at $25^{\circ} \mathrm{C}$ is given as follows:

$$
\operatorname{IE}(\%)=2.39 C+2.47 D-0.02 C D
$$

where $I E$ is the inhibition efficiency, $C$ is the composition of GA and $D$ is the composition of HPMC, respectively. When dealing with formulations of a two-component mixture or more, in this case, GA and HPMC, it is worth to know if the components are working synergistically (better together) or antagonistically (better alone). Based on the last coefficient of Equation (8) (-0.02), it seemed that the polymers exhibited antagonistic effect [78].

The response trace plot of various GA and HPMC combinations is depicted in Figure 8 to represent the correlation. As evident from the plot, the best inhibition efficiency was obtained at the extreme ends of the formulation, whereby only a single polymer is incorporated in the tablet. With both polymers' combination, the tablets showed gradual inhibition efficiency reduction. This reduction is an indication that GA and HPMC do not work very well together and is said to have an antagonistic effect on the performance [78]. Accordingly, only the best two formulations were selected for further investigations.

\subsubsection{Tensile Strength, Disintegration Time and Dissolution Profile}

In the previous section, the effect of different tablet formulations on the corrosion inhibition efficiency was investigated, and two best tablet formulations were determined (T2 and T3). Those two tablets, as well as a control tablet (T1) were further investigated in terms of their tensile strength, disintegration time and dissolution profile. The tensile strength is an essential mechanical property to determine the tablets' integrity. It is greatly affected by the excipients used in the formulation and their particle size distribution [79]. The tensile strengths of tablet T1, T2 and T3 are compiled in Table 9. As evident from the data, the highest strength was exhibited by T3 (0.243 MPa), followed by T1 (0.130 MPa) and T2 (0.099 MPa). T2 that was incorporated with GA exhibited inferior mechanical strength. The low strength is probably due to GA's brittleness, which caused breakage within the compressed powder, hence damaging the tablet's overall structure [80]. On the other hand, the addition of HPMC in the formulation improved the tensile strength of T3 by more than twofold compared to the control. This result is consistent with those of Siow et al. [81] who found out that incorporating HPMC showed positive contribution to mannitol tablets' strength. 


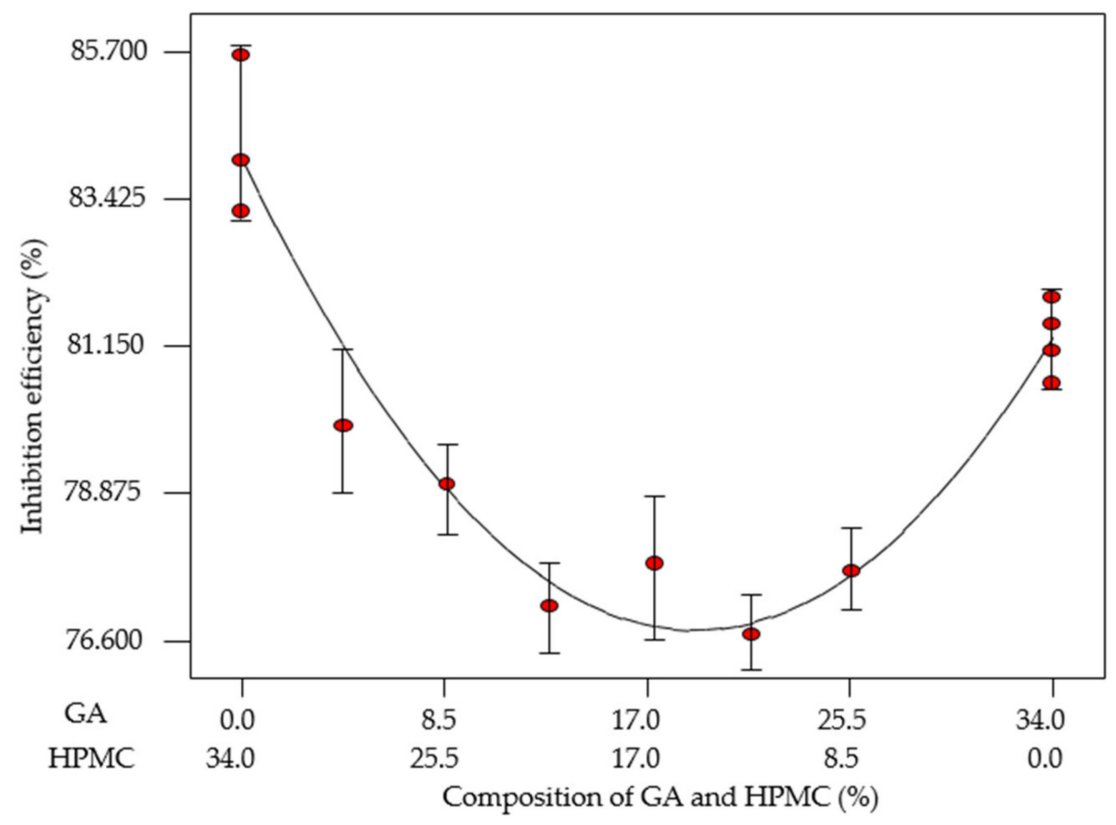

Figure 8. Two-component mixture plot; inhibition efficiencies of mild steel in $1 \mathrm{M} \mathrm{HCl}$ at different EFB-H tablet formulations at $25^{\circ} \mathrm{C}$.

Table 9. Formulations, inhibition efficiencies and tablet properties of selected tablets.

\begin{tabular}{|c|c|c|c|c|c|c|}
\hline \multirow{2}{*}{ Tablet } & \multicolumn{3}{|c|}{ Formulation $(\% w / w)$} & \multirow{2}{*}{$I E_{W L}(\%)$} & \multirow{2}{*}{$\begin{array}{c}\text { Tensile } \\
\text { Strength (MPa) }\end{array}$} & \multirow{2}{*}{$\begin{array}{l}\text { Disintegration } \\
\text { Time (min) }\end{array}$} \\
\hline & EFB-H & GA & HPMC & & & \\
\hline $\mathrm{T} 1$ & 100.0 & 0.0 & 0.0 & 87.12 & $0.130 \pm 0.027$ & $63.00 \pm 1.00$ \\
\hline $\mathrm{T} 2$ & 66.0 & 34.0 & 0.0 & 81.28 & $0.099 \pm 0.017$ & $53.00 \pm 3.00$ \\
\hline T3 & 66.0 & 0.0 & 34.0 & 84.30 & $0.243 \pm 0.006$ & $152.00 \pm 2.00$ \\
\hline
\end{tabular}

Note: $I E_{W L}$ is inhibition efficiency from weight loss method; Values are mean \pm standard deviation.

In terms of the tablets' disintegration time in $1 \mathrm{M} \mathrm{HCl}$ media, $\mathrm{T} 3$ showed a longer disintegrating period than T1 and T2. This finding indicates that HPMC better facilitates the slower release of EFB-H to the corrosive solution. HPMC is excellent in slowing down the disintegration due to its high hydrophilicity, enabling the polymer to swell and become gelatinised upon contact with water [82]. The formation of the polymer gel retards the diffusion of active ingredients and the tablet's erosion. From the corrosion inhibition perspective, the slow release of inhibitor compounds from a matrix will lead to sustained service life of an inhibitor [83].

The dissolution profile is also an essential property of a corrosion inhibitor tablet as it is crucial to have a sufficient and continuous supply of inhibitor over time to avoid localised corrosion. The dissolution profiles of T1, T2 and T3 are illustrated in Figure 9. Evidently, the plot revealed that each tablet's dissolution behaviour was undoubtedly distinct from each other. A linear dissolution trend is observed for the control tablet starting from the initial time up to $10 \mathrm{~min}$ and from $20 \mathrm{~min}$ to $60 \mathrm{~min}$ in the media (T1). This constant supply of inhibitor explains the excellent corrosion inhibition of T1. For the case of T2, the dissolution rate was not uniform, which starts relatively faster than T1 and T3, and fluctuates starting from 20 to 60 min of immersion. This disintegration manner is quite risky for corrosion inhibition application. The first reason is that with the rapid release of the inhibitor, the molecules degrade faster, and hence it will not be efficient in the long run [77]. Secondly, with delayed inhibitor release, the concentration might fall below the minimum at a certain time. For the case of EFB-H that is a mixed type inhibitor, lower concentration might induce localised or pitting corrosion in some area where the surface is not fully covered by the inhibitor compounds [84]. T3 showed the best dissolution action among all the tablets, 
which was gradual until it completely dissolves. Even though showing some slight delay in disintegration at the 120th minute, the overall behaviour is still better than T1 and T2. Similar dissolution behaviour of other HPMC incorporated tablets such as mineral salt tablet and mannitol tablet were reported in the literature [81,85].

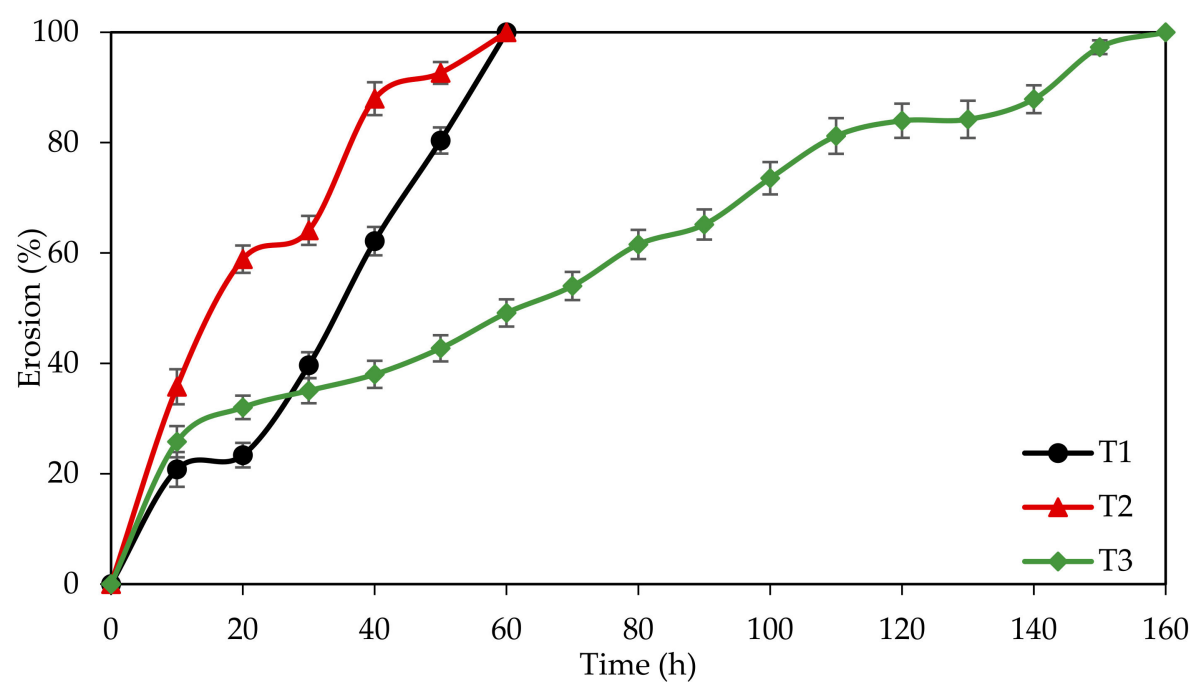

Figure 9. Dissolution profiles of $\mathrm{T} 1, \mathrm{~T} 2$ and $\mathrm{T} 3$ in $1 \mathrm{M} \mathrm{HCl}$ at $25^{\circ} \mathrm{C}$ and $100 \mathrm{rpm}$ of agitation speed.

In general, based on the tensile strength, disintegration time and dissolution profile, $\mathrm{T} 3$ portrayed the best performance, followed by $\mathrm{T} 1$ and $\mathrm{T} 2$. The addition of polymer in the EFB-H tablet had modified the tablet properties substantially. Despite the promising results, the tensile strength of $\mathrm{T} 3$ is still meagre $(0.243 \mathrm{MPa})$ compared to other HPMC bound tablets reported elsewhere $(0.16$ to $1.75 \mathrm{MPa})[81,86]$. Hence, improvements should be made to enhance the tablet strength further. Moreover, the dissolution test conducted in the study is based on a standard procedure meant for pharmaceutical application. Even though beneficial for this preliminary study, a more specific method for corrosion inhibition application should be developed for more accurate result. Additionally, the likelihood of added polymers participating in the corrosion inhibition mechanism cannot be ruled out as numerous studies have demonstrated that polymers, such as GA, are excellent corrosion inhibitors. Since there is hardly any reported application of compressed tablets in the field of corrosion inhibition except for one patented technology [14], further work is required to address this matter. In addition, there are various other properties that should be considered, but only the crucial parameters relevant for corrosion inhibition are investigated at this stage.

\subsubsection{Extended Weight Loss Study}

To prove the EFB-H tablet's effectiveness at an extended time, a prolonged weight loss study (120 to $720 \mathrm{~h}$ ) for both powder and tablet forms of EFB-H was performed. T3 formulation was selected for this examination due to its excellent properties, as discussed in the previous section. The trends of the inhibition efficiency of T3 and EFB-H powder at extended immersion times are illustrated in Figure 10.

As expected, EFB-H powder showed a reduction in inhibition efficiency after $120 \mathrm{~h}$ of immersion. Contrarily, the tablet showed nearly persistent performances over $360 \mathrm{~h}$ despite having slightly lower efficacies relative to the powder at $120 \mathrm{~h}$ of immersion time. The longer inhibitive time of the tablet is explicable to the sustained release of EFB$\mathrm{H}$ active compounds. The gradual release prevents desorption and degradation of the inhibitor molecules, which are the leading causes of efficacy reduction at longer immersion time $[10,77,87]$. Beyond $360 \mathrm{~h}$, the tablet exhibited some inhibition efficiency reduction, but it was not as extensive as portrayed by the powder. The depletion of inhibitor compounds possibly causes a decrease in performance. A commercial tablet for an industrial water 
treatment system that includes polymers, biocide, surfactant, scale inhibitor and corrosion inhibitor in the formulation with a bigger tablet diameter, approximately $70 \mathrm{~mm}$, could hold up to six months [14]. Therefore, increasing the dose of EFB-H and the size of the tablet may extend the shelf life of the EFB-H tablet for longer time.

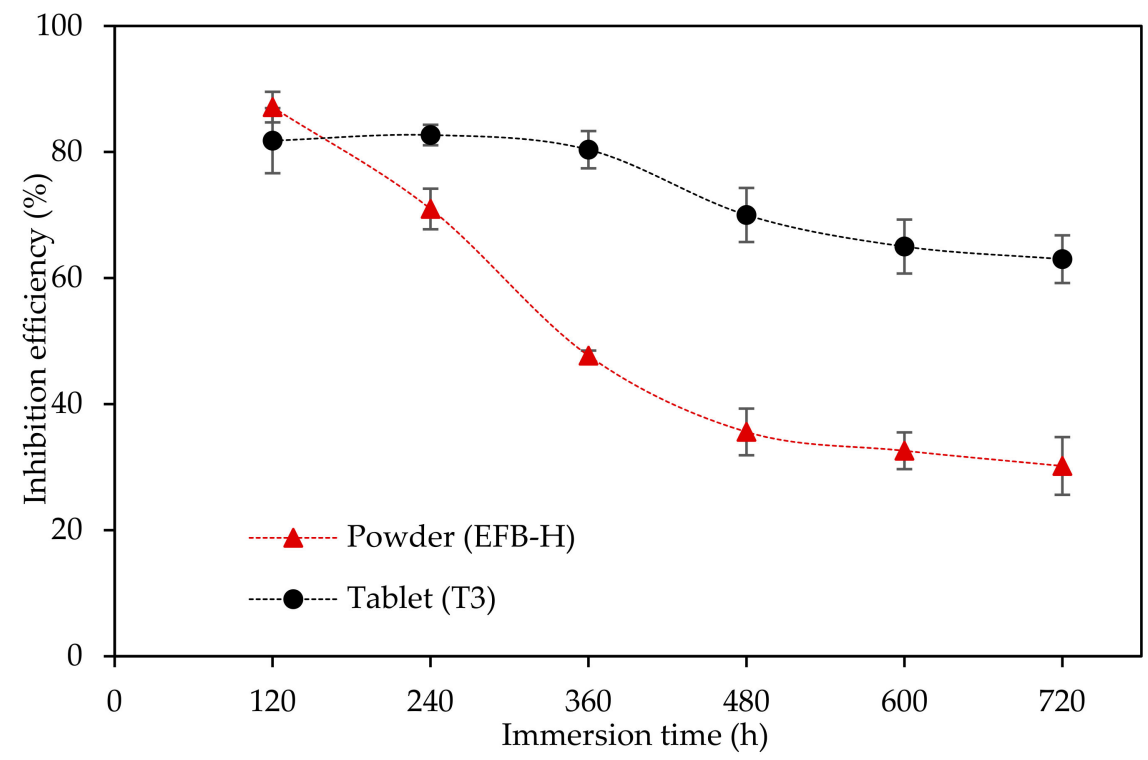

Figure 10. Inhibition efficiencies of mild steel in $1 \mathrm{M} \mathrm{HCl}$ at different forms of EFB-Hs at different immersion times at $25^{\circ} \mathrm{C}$.

On the basis of this finding, it can be deduced that the sustained release tablet has a longer-lasting inhibition effect than the powder. Therefore, the implementation of a well-acknowledged pharmaceutical technology in corrosion engineering is proven to be successful. While preliminary, this finding leads to a number of possibilities and offers a revolutionary step in the industrialisation of nature-based corrosion inhibitors, which is a huge and unbridged gap between research and commercialisation [88].

\section{Conclusions}

In general, this project aimed to develop a controlled release EFB-H inhibitor tablet to inhibit mild steel acid corrosion. This study contemplated the conventional fundamental study of a corrosion inhibitor as well as its engineering application. Based on the findings, it can be summarized that the presence of heteroatoms and reactive functional groups in EFB-H has been validated through FTIR analysis, and 89.51\% of hemicellulose was quantified via compositional analysis. In addition, the PDP measurement has shown that EFB-H inhibited mild steel corrosion by a mixed mechanism of anodic and cathodic reactions retardation. A reduction of current density and corrosion rate was observed as the dosage was increased, reflecting that more inhibitor molecules are adsorbed at higher dosages. From EIS analysis, it has been revealed that EFB-H increased the charge transfer resistance from metal to the solution and reduced the double layer capacitance within the metal/electrolyte interface. Furthermore, it was discovered that the corrosion inhibition system could be integrated into a modified Randles circuit with a CPE. RSM/CCD optimization has unveiled that the optimum point for a maximum inhibition efficiency (87.11\%) was at $0.33 \mathrm{~g}$ of EFB-H dosage and $120 \mathrm{~h}$ of immersion time. Regarding tablet development, T3 with EFB-H:GA:HPMC ratio of 66:0:34 portrayed the best tensile strength (0.243 MPa), disintegration time (152 $\mathrm{min})$, dissolution behavior and adequate corrosion inhibition performance $(84.30 \%)$. In comparison with EFB-H in powder form, the EFB-H tablet exhibited a longer-lasting inhibition effect, which was $360 \mathrm{~h}$ compared to $120 \mathrm{~h}$ for powder. Overall, these results suggest that the EFB-H tablet has been successfully developed, and its enhanced effective inhibition time has been experimentally proven. 
The innovative approach of developing a controlled release inhibitor tablet may have unraveled the emerging issues when dealing with natural inhibitors. This pioneering discovery provides a colossal foundation to utilize nature-based inhibitors for commercial applications. The precise inhibition mechanism of EFB-H remains to be elucidated. Hence, a study that assesses the inhibition mechanism through adsorption isotherm study, comprehensive chemical characterization, quantum chemical calculation and molecular dynamic simulation will need to be carried out in the future.

Author Contributions: Writing—original draft preparation, N.I.N.H.; writing—review and editing, S.S.; supervision, S.S., Y.A.Y. and N.K.K. All authors have read and agreed to the published version of the manuscript.

Funding: This research was funded by Universiti Putra Malaysia, Putra Grant IPS, grant number 9657500.

Institutional Review Board Statement: Not applicable.

Informed Consent Statement: Not applicable.

Data Availability Statement: Data available on request from the authors.

Conflicts of Interest: The authors declare no conflict of interest.

\section{References}

1. Chauhan, D.S.; Mazumder, M.J.; Quraishi, M.; Ansari, K. Chitosan-cinnamaldehyde Schiff base: A bioinspired macromolecule as corrosion inhibitor for oil and gas industry. Int. J. Biol. Macromol. 2020, 158, 127-138. [CrossRef]

2. Monticelli, C. Corrosion Inhibitors. In Encyclopedia of Interfacial Chemistry: Surface Science and Electrochemistry; Elsevier: Oxford, UK, 2018; pp. 164-171.

3. Tamalmani, K.; Husin, H. Review on Corrosion Inhibitors for Oil and Gas Corrosion Issues. Appl. Sci. 2020, 10, 3389. [CrossRef]

4. Gouamid, M.; Zenkhri, L.; Benhamida, S.; Chebouat, E.; Charradi, K. Inhibitive and Adsorption behaviour of date Palm Hemicellulose on Mild Steel Corrosion in Sulfuric Acid Media. Asian J. Res. Chem. 2019, 12, 303. [CrossRef]

5. Guedes, D.; Martins, G.R.; Jaramillo, L.Y.A.; Dias, D.S.B.; da Silva, A.J.R.; Lutterbach, M.T.S.; Reznik, L.Y.; Sérvulo, E.F.C.; Alviano, C.S.; Alviano, D.S. Proanthocyanidins with Corrosion Inhibition Activity for AISI 1020 Carbon Steel under Neutral pH Conditions of Coconut (Cocos nucifera L.) Husk Fibers. ACS Omega 2021, 6, 6893-6901. [CrossRef]

6. Komalasari; Zultiniar; Karim, A.R.M.; Susanto, R.; Azhari, I.; Utami, S.P.; Heltina, D. Biomass Extraction as Green Corrosion Inhibitor for Low Carbon Steel in Hydrochloric Acid Solution. J. Phys. Conf. Ser. 2020, 1655. [CrossRef]

7. De Lima, K.C.D.S.; Paiva, V.M.; Perrone, D.; Ripper, B.; Simoes, G.; Rocco, M.L.M.; da Veiga, A.G.; D’Elia, E. Glycine max meal extracts as corrosion inhibitor for mild steel in sulphuric acid solution. J. Mater. Res. Technol. 2020, 9, 12756-12772. Available online: https: / / www.sciencedirect.com/science/article/pii/S2238785420317427 (accessed on 15 June 2021). [CrossRef]

8. El-Hashemy, M.A.; Sallam, A. The inhibitive action of Calendula officinalis flower heads extract for mild steel corrosion in $1 \mathrm{M}$ $\mathrm{HCl}$ solution. J. Mater. Res. Technol. 2020, 9, 13509-13523. [CrossRef]

9. Chahul, H.F.; Danat, T.B.; Wuana, R.A. Corrosion inhibition studies on the influence of colocasia esculenta leaves extract on mild steel in $1.0 \mathrm{M} \mathrm{HCl}$. J. Mater. Environ. Sci. 2019, 10, 266-273.

10. Asfia, M.P.; Rezaei, M.; Bahlakeh, G. Corrosion prevention of AISI 304 stainless steel in hydrochloric acid medium using garlic extract as a green corrosion inhibitor: Electrochemical and theoretical studies. J. Mol. Liq. 2020, 315, 113679. [CrossRef]

11. Wang, C.; Chen, J.; Hu, B.; Liu, Z.; Wang, C.; Han, J.; Su, M.; Li, Y.; Li, C. Modified chitosan-oligosaccharide and sodium silicate as efficient sustainable inhibitor for carbon steel against chloride-induced corrosion. J. Clean. Prod. 2019, 238, 117823. [CrossRef]

12. Ong, G.; Kasi, R.; Subramaniam, R. A review on plant extracts as natural additives in coating applications. Prog. Org. Coat. 2021, 151, 106091. [CrossRef]

13. Pineda Hernández, D.A.; Restrepo Parra, E.; Arango Arango, P.J.; Segura Giraldo, B.; Acosta Medina, C.D. Innovative Method for Coating of Natural Corrosion Inhibitor Based on Artemisia vulgaris. Materials 2021, 14, 2234. [CrossRef]

14. Haag, A.P.; Relenyi, A.G. Slow Release Tablet Composition for Treating Industrial Water Systems. US Patent 9,090,495 B2, 28 July 2015.

15. Wondi, M.H.; Shamsudin, R.; Yunus, R.; Alsultan, A.; Iswardi, A.H. Centrifugal separation-assisted and extraction of crude palm oil from separated mesocarp fiber: Central composite design optimization. J. Food Process Eng. 2020, 43, e13426. [CrossRef]

16. Haris, N.I.N.; Sobri, S.; Kassim, N. Oil palm empty fruit bunch extract as green corrosion inhibitor for mild steel in hydrochloric acid solution: Central composite design optimization. Mater. Corros. 2019, 70, 1111-1119. [CrossRef]

17. Haris, N.I.N.; Sobri, S.; Yusof, Y.A.; Kassim, N. Oil palm empty fruit bunch extract and powder as an eco-friendly corrosion inhibitor for mild steel: A comparison study. Mater. Corros. 2019, 70, 2326-2333. [CrossRef] 
18. Woiciechowski, A.L.; Neto, C.J.D.; de Souza Vandenberghe, L.P.; de Carvalho Neto, D.P.; Sydney, A.C.N.; Letti, L.A.J.; Karp, S.G.; Torres, L.A.Z.; Soccol, C.R. Lignocellulosic biomass: Acid and alkaline pretreatments and their effects on biomass recalcitranceConventional processing and recent advances. Bioresour. Technol. 2020, 304, 122848. Available online: https:/ / www.sciencedirect. com/science/article/pii/S0960852420301176 (accessed on 30 June 2021). [CrossRef]

19. Palamae, S.; Dechatiwongse, P.; Choorit, W.; Chisti, Y.; Prasertsan, P. Cellulose and hemicellulose recovery from oil palm empty fruit bunch (EFB) fibers and production of sugars from the fibers. Carbohydr. Polym. 2017, 155, 491-497. [CrossRef]

20. Kim, S.J.; Um, B.H. Process Variable Optimization of Kenaf Two-Stage Fractionation Based on Dilute Hydrochloric Acid Followed by Ethanol Organosolv for Component Separation. BioEnergy Res. 2020, 13, 249-259. [CrossRef]

21. Ioelovich, M. Methods for determination of chemical composition of plant biomass. Sci. Isreal Technol. Advant. 2015, 17, 208-214.

22. Ech-Chihbi, E.; Nahlé, A.; Salim, R.; Benhiba, F.; Moussaif, A.; El-Hajjaji, F.; Oudda, H.; Guenbour, A.; Taleb, M.; Warad, I.; et al. Computational, MD simulation, SEM/EDX and experimental studies for understanding adsorption of benzimidazole derivatives as corrosion inhibitors in $1.0 \mathrm{M} \mathrm{HCl}$ solution. J. Alloys Compd. 2020, 844, 155842. [CrossRef]

23. Djenane, M.; Chafaa, S.; Chafai, N.; Kerkour, R.; Hellal, A. Synthesis, spectral properties and corrosion inhibition efficiency of new ethyl hydrogen [(methoxyphenyl) (methylamino) methyl] phosphonate derivatives: Experimental and theoretical investigation. J. Mol. Struct. 2019, 1175, 398-413. [CrossRef]

24. Gamry Instruments. Getting Started with Electrochemical Corrosion Measurement Rev 2; Gamry Instruments Inc.: Warminster, PA, USA, 2017.

25. Sanaei, Z.; Ramezanzadeh, M.; Bahlakeh, G.; Ramezanzadeh, B. Use of Rosa canina fruit extract as a green corrosion inhibitor for mild steel in $1 \mathrm{M} \mathrm{HCl}$ solution: A complementary experimental, molecular dynamics and quantum mechanics investigation. J. Ind. Eng. Chem. 2019, 69, 18-31. [CrossRef]

26. Quraishi, M.A.; Chauhan, D.S.; Saji, V.S. Heterocyclic Corrosion Inhibitors; Elsevier: Amsterdam, The Netherlands, $2020 ;$ pp. 1-298.

27. Lgaz, H.; Masroor, S.; Chafiq, M.; Damej, M.; Brahmia, A.; Salghi, R.; Benmessaoud, M.; Ali, I.H.; Alghamdi, M.M.; Chaouiki, A.; et al. Evaluation of 2-Mercaptobenzimidazole Derivatives as Corrosion Inhibitors for Mild Steel in Hydrochloric Acid. Metals 2020, 10, 357. [CrossRef]

28. Khalid, N.I.; Sulaiman, N.S.; Ab Aziz, N.; Taip, F.S.; Sobri, S.; Ab Rashid, N.-K.M. Optimization of Electrolysis Parameters for Green Sanitation Chemicals Production Using Response Surface Methodology. Processes 2020, 8, 792. [CrossRef]

29. Yusof, Y.; Salleh, F.M.; Chin, N.; Talib, R.A. The drying and tabletting of pitaya powder. J. Food Process Eng. $2012,35,763-771$. [CrossRef]

30. Bisharat, L.; AlKhatib, H.; Al Muhaissen, S.; Quodbach, J.; Blaibleh, A.; Cespi, M.; Berardi, A. The influence of ethanol on superdisintegrants and on tablets disintegration. Eur. J. Pharm. Sci. 2019, 129, 140-147. Available online: https://www. sciencedirect.com/science/article/pii/S0928098719300120 (accessed on 11 July 2021). [CrossRef]

31. Bykov, I. Characterization of Natural and Technical Lignins Using FTIR Spectroscopy; Lulea University of Technology: Luleå, Swiss, 2008.

32. Zianor Azrina, Z.A.; Beg, M.D.H.; Rosli, M.Y.; Ramli, R.; Junadi, N.; Alam, A.K.M.M. Spherical nanocrystalline cellulose (NCC) from oil palm empty fruit bunch pulp via ultrasound assisted hydrolysis. Carbohydr. Polym. 2017, 162, 115-120. [CrossRef]

33. Lamaming, J.; Hashim, R.; Sulaiman, O.; Leh, C.P.; Sugimoto, T.; Nordin, N.A. Cellulose nanocrystals isolated from oil palm trunk. Carbohydr. Polym. 2015, 127, 202-208. [CrossRef]

34. Poletto, M.; Ornaghi, J.H.L.; Zattera, A.J. Native Cellulose: Structure, Characterization and Thermal Properties. Materials 2014, 7, 6105-6119. [CrossRef]

35. Aranguren, M.I.; Mosiewicki, M.A.; Marcovich, N.E. Spectroscopic Characterization of Renewable Nanoparticles and Their Composites. In Biopolymer Nanocomposites: Processing, Properties, and Applications; John Wiley \& Sons: Hoboken, NJ, USA, 2013; pp. 509-540.

36. Le Troedec, M.; Sedan, D.; Peyratout, C.; Bonnet, J.P.; Smith, A.; Guinebretiere, R.; Gloaguen, V.; Krausz, P. Influence of various chemical treatments on the composition and structure of hemp fibres. Compos. Part A Appl. Sci. Manuf. 2008, 39, 514-522. [CrossRef]

37. Bekiaris, G.; Koutrotsios, G.; Tarantilis, P.A.; Pappas, C.S.; Zervakis, G.I. FTIR assessment of compositional changes in lignocellulosic wastes during cultivation of Cyclocybe cylindracea mushrooms and use of chemometric models to predict production performance. J. Mater. Cycles Waste Manag. 2020, 22, 1027-1035. [CrossRef]

38. Liu, Y.; Hu, T.; Wu, Z.; Zeng, G.; Huang, D.; Shen, Y.; He, X.; Lai, M.; He, Y. Study on biodegradation process of lignin by FTIR and DSC. Environ. Sci. Pollut. Res. 2014, 21, 14004-14013. [CrossRef] [PubMed]

39. Boukir, A.; Fellak, S.; Doumenq, P. Structural characterization of Argania spinosa Moroccan wooden artifacts during natural degradation progress using infrared spectroscopy (ATR-FTIR) and X-Ray diffraction (XRD). Heliyon 2019, 5, e02477. [CrossRef]

40. Hussin, M.H.; Samad, N.A.; Latif, N.H.A.; Rozuli, N.A.; Yusoff, S.B.; Gambier, F.; Brosse, N. Production of oil palm (Elaeis guineensis) fronds lignin-derived non-toxic aldehyde for eco-friendly wood adhesive. Int. J. Biol. Macromol. 2018, 113, 1266-1272. [CrossRef]

41. Lyu, G.; Wu, Q.; Li, T.; Jiang, W.; Ji, X.; Yang, G. Thermochemical properties of lignin extracted from willow by deep eutectic solvents (DES). Cellulose 2019, 26, 8501-8511. [CrossRef]

42. Célino, A.; Fréour, S.; Jacquemin, F.; Casari, P. Characterization and modeling of the moisture diffusion behavior of natural fibers. J. Appl. Polym. Sci. 2013, 130, 297-306. [CrossRef] 
43. Sun, X.-F.; Jing, Z.; Fowler, P.; Wu, Y.; Rajaratnam, M. Structural characterization and isolation of lignin and hemicelluloses from barley straw. Ind. Crops Prod. 2011, 33, 588-598. [CrossRef]

44. Kumneadklang, S.; O-Thong, S.; Larpkiattaworn, S. Characterization of cellulose fiber isolated from oil palm frond biomass. Mater. Today Proc. 2019, 17, 1995-2001. [CrossRef]

45. Yu, J.; Zhu, Y.; Ma, H.; Liu, L.; Hu, Y.; Xu, J.; Wang, Z.; Fan, Y. Contribution of hemicellulose to cellulose nanofiber-based nanocomposite films with enhanced strength, flexibility and UV-blocking properties. Cellulose 2019, 26, 6023-6034. [CrossRef]

46. Alaneme, K.; Olusegun, S.; Alo, A. Corrosion inhibitory properties of elephant grass (Pennisetum purpureum) extract: Effect on mild steel corrosion in 1M HCl solution. Alex. Eng. J. 2016, 55, 1069-1076. [CrossRef]

47. Alaneme, K.K.; Daramola, Y.S.; Olusegun, S.J.; Afolabi, A.S. Corrosion inhibition and adsorption characteristics of rice husk extracts on mild steel immersed in 1M H2SO4 and $\mathrm{HCl}$ solutions. Int. J. Electrochem. Sci. 2015, 10, 3553-3567.

48. Schmatz, A.A.; Tyhoda, L.; Brienzo, M. Sugarcane biomass conversion influenced by lignin. Biofuels Bioprod. Biorefin. 2020, 14, 469-480. [CrossRef]

49. Chen, X.-F.; Zhang, L.-Q.; Huang, C.; Xiong, L.; Li, H.-L.; Wang, C.; Zhao, C.; Huang, Q.-L.; Chen, X.-D. Adsorption Study of Acid Soluble Lignin Removal from Sugarcane Bagasse Hydrolysate by a Self-Synthesized Resin for Lipid Production. Appl. Biochem. Biotechnol. 2019, 188, 585-601. [CrossRef]

50. Altemimi, A.; Lakhssassi, N.; Baharlouei, A.; Watson, D.G.; Lightfoot, D.A. Phytochemicals: Extraction, Isolation, and Identification of Bioactive Compounds from Plant Extracts. Plants 2017, 6, 42. [CrossRef]

51. Ferdosi Heragh, M.; Tavakoli, H. Electrochemical properties of a new green corrosion inhibitor derived from prosopis farcta for St37 steel in $1 \mathrm{M}$ hydrochloric acid. Met. Mater. Int. 2020, 26, 1654-1663. [CrossRef]

52. Nwankwo, H.U.; Akpan, E.D.; Olasunkanmi, L.O.; Verma, C.; Al-Mohaimeed, A.M.; Al Farraj, D.A.; Ebenso, E.E. N-substituted carbazoles as corrosion inhibitors in microbiologically influenced and acidic corrosion of mild steel: Gravimetric, electrochemical, surface and computational studies. J. Mol. Struct. 2021, 1223, 129328. [CrossRef]

53. El Aatiaoui, A.; Koudad, M.; Chelfi, T.; Erkan, S.; Azzouzi, M.; Aouniti, A.; Savaş, K.; Kaddouri, M.; Benchat, N.; Oussaid, A. Experimental and theoretical study of new Schiff bases based on imidazo(1,2-a)pyridine as corrosion inhibitor of mild steel in $1 \mathrm{M}$ HCl. J. Mol. Struct. 2021, 1226, 129372. [CrossRef]

54. Belakhdar, A.; Ferkous, H.; Djellali, S.; Sahraoui, R.; Lahbib, H.; Ben Amor, Y.; Erto, A.; Balsamo, M.; Benguerba, Y. Computational and experimental studies on the efficiency of Rosmarinus officinalis polyphenols as green corrosion inhibitors for XC48 steel in acidic medium. Colloids Surf. A Physicochem. Eng. Asp. 2020, 606, 125458. Available online: https://www.sciencedirect.com/ science/article/pii/S0927775720310517 (accessed on 3 May 2021). [CrossRef]

55. Hsissou, R.; Abbout, S.; Seghiri, R.; Rehioui, M.; Berisha, A.; Erramli, H.; Assouag, M.; Elharfi, A. Evaluation of corrosion inhibition performance of phosphorus polymer for carbon steel in [1 M] HCl: Computational studies (DFT, MC and MD simulations). J. Mater. Res. Technol. 2020, 9, 2691-2703. [CrossRef]

56. Wang, X.; Zhang, Q.; Jiang, H.; Gu, Y.; Li, X.; Xu, L.-L. Pueraria lobata leaf extract as green corrosion inhibitor for low carbon steel in 1.0 M HCl solution. Res. Chem. Intermed. 2021, 47, 1051-1069. [CrossRef]

57. Pal, A.; Das, C. A novel use of solid waste extract from tea factory as corrosion inhibitor in acidic media on boiler quality steel. Ind. Crops Prod. 2020, 151, 112468. [CrossRef]

58. Kakaei, K.; Esrafili, M.D.; Ehsani, A. Graphene and Anticorrosive Properties. In Graphene Surfaces; Kakaei, K., Esrafili, M.D., Ehsani, A.B.T., Eds.; Elsevier: Amsterdam, The Netherlands, 2019; pp. 303-337. Available online: https:/ / www.sciencedirect. com/science/article/pii/B9780128145234000083 (accessed on 2 August 2021).

59. Fernández-Solis, C.D.; Vimalanandan, A.; Altin, A.; Mondragón-Ochoa, J.S.; Kreth, K.; Keil, P.; Erbe, A. Fundamentals of electrochemistry, corrosion and corrosion protection. In Soft Matter at Aqueous Interfaces; Springer: Berlin/Heidelberg, Germany, 2016; pp. 26-70.

60. Kumari, P.; Yadav, M.; Obot, I.B. Investigation on corrosion protection behavior and adsorption of carbohydrazide-pyrazole compounds on mild steel in 15\% HCl solution: Electrochemical and computational approach. J. Mol. Liq. 2020, 314 , 113513. [CrossRef]

61. Ellis, C.L.; Smith, E.; Javaid, H.; Berns, G.; Venkataraman, D. Ion Migration in Hybrid Perovskites. In Perovskite Photovoltaics: Basic to Advanced Concepts and Implementation; Elsevier: Amsterdam, The Netherlands, 2018; pp. 163-196.

62. Guo, L.; Tan, J.; Kaya, S.; Leng, S.; Li, Q.; Zhang, F. Multidimensional insights into the corrosion inhibition of 3,3-dithiodipropionic acid on Q235 steel in H2SO4 medium: A combined experimental and in silico investigation. J. Colloid Interface Sci. 2020, 570, 116-124. [CrossRef]

63. Mohd, N.K.; Yeong, S.K.; Ibrahim, N.A.; Nor, S.M.M.; Chan, C.H.; Tang, S.W.; Lim, W.H.; Idris, Z. Corrosion inhibition, adsorption behaviour and thermodynamic properties of n-cinnamalidene palmitohydrazide on mild steel in hydrochloric acid solution. J. Oil Palm Res. 2020, 32, 124-138. [CrossRef]

64. Aslam, R.; Mobin, M.; Shoeb, M.; Murmu, M.; Banerjee, P. Proline nitrate ionic liquid as high temperature acid corrosion inhibitor for mild steel: Experimental and molecular-level insights. J. Ind. Eng. Chem. 2021, 100, 333-350. Available online: https:/ / www.sciencedirect.com/science/article/pii/S1226086X21002677 (accessed on 8 June 2021). [CrossRef]

65. Feliu, S. Electrochemical impedance spectroscopy for the measurement of the corrosion rate of magnesium alloys: Brief review and challenges. Metals 2020, 10, 775. [CrossRef] 
66. Farhadian, A.; Rahimi, A.; Safaei, N.; Shaabani, A.; Abdouss, M.; Alavi, A. A theoretical and experimental study of castor oil-based inhibitor for corrosion inhibition of mild steel in acidic medium at elevated temperatures. Corros. Sci. 2020, $175,108871$. [CrossRef]

67. Fernandes, C.M.; Pina, V.G.; Alvarez, L.X.; de Albuquerque, A.C.F.; Júnior, F.M.D.S.; Barrios, A.M.; Velasco, J.A.; Ponzio, E.A. Use of a theoretical prediction method and quantum chemical calculations for the design, synthesis and experimental evaluation of three green corrosion inhibitors for mild steel. Colloids Surf. A 2020, 599, 124857. [CrossRef]

68. Breynaert, E.; Houlleberghs, M.; Radhakrishnan, S.; Grübel, G.; Taulelle, F.; Martens, J.A. Water as a tuneable solvent: A perspective. Chem. Soc. Rev. 2020, 49, 2557-2569. [CrossRef]

69. Rousseva, S.; Besten, H.D.; Van Kooij, F.S.; Doting, E.L.; Doumon, N.Y.; Douvogianni, E.; Koster, L.J.A.; Hummelen, J.C. Reaching a Double-Digit Dielectric Constant with Fullerene Derivatives. J. Phys. Chem. C 2020, 124, 8633-8638. [CrossRef]

70. Torres, A.R.; Cisneros, M.G.V.; Chavarín, J.U.; Arteaga, C.C.; Rodríguez, M.A.V. The use of Brugmansia arborea as a green corrosion inhibitor for AISI 1018 carbon steel in acid media. Green Chem. Lett. Rev. 2021, 14, 107-117. [CrossRef]

71. Arukalam, I.O.; Madu, I.O.; Ijomah, N.T.; Ewulonu, C.M.; Onyeagoro, G.N. Acid Corrosion Inhibition and Adsorption Behaviour of Ethyl Hydroxyethyl Cellulose on Mild Steel Corrosion. J. Mater. 2014, 2014, 1-11. [CrossRef]

72. Edoziuno, F.O.; Adediran, A.A.; Odoni, B.; Akinwekomi, A.; Adesina, O.; Oki, M. Optimization and development of predictive models for the corrosion inhibition of mild steel in sulphuric acid by methyl-5-benzoyl-2-benzimidazole carbamate (mebendazole). Cogent Eng. 2020, 7, 1714100. [CrossRef]

73. Abbout, S.; Zouarhi, M.; Chebabe, D.; Damej, M.; Berisha, A.; Hajjaji, N. Galactomannan as a new bio-sourced corrosion inhibitor for iron in acidic media. Heliyon 2020, 6, e03574. [CrossRef]

74. Onyeachu, I.B.; Solomon, M.M.; Umoren, S.A.; Obot, I.B.; Sorour, A.A. Corrosion inhibition effect of a benzimidazole derivative on heat exchanger tubing materials during acid cleaning of multistage flash desalination plants. Desalination 2020, $479,114283$. [CrossRef]

75. Ye, Y.; Zou, Y.; Jiang, Z.; Yang, Q.; Chen, L.; Guo, S.; Chen, H. An effective corrosion inhibitor of N doped carbon dots for Q235 steel in $1 \mathrm{M} \mathrm{HCl}$ solution. J. Alloys Compd. 2020, 815, 152338. [CrossRef]

76. Murmu, M.; Saha, S.K.; Murmu, N.C.; Banerjee, P. Effect of stereochemical conformation into the corrosion inhibitive behaviour of double azomethine based Schiff bases on mild steel surface in $1 \mathrm{~mol} \mathrm{~L}-1 \mathrm{HCl}$ medium: An experimental, density functional theory and molecular dynamics simulation study. Corros. Sci. 2019, 146, 134-151. [CrossRef]

77. Barmatov, E.; Hughes, T. Degradation of a schiff-base corrosion inhibitor by hydrolysis, and its effects on the inhibition efficiency for steel in hydrochloric acid. Mater. Chem. Phys. 2021, 257, 123758. [CrossRef]

78. Anderson, M.J.; Whitcomb, P.J.; Bezener, M.A. Getting Your Toe into Mixtures. In Formulation Simplified; Routledge: London, UK, 2018; pp. 1-30.

79. Lee, W.B.; Widjaja, E.; Heng, P.W.S.; Chan, L.W. Effect of excipient particle size distribution variability on compact tensile strength; and its in-line prediction by force-displacement and force-time profiling. Eur. J. Pharm. Sci. 2021, 159, 105703. [CrossRef]

80. Ogunjimi, A.; Alebiowu, G. Material and tableting properties of Azadirachta indica gum with reference to official acacia gum. Acta Pol. Pharm. 2014, 71, 107-118.

81. Siow, C.R.S.; Heng, P.W.S.; Chan, L.W. A study on the impact of HPMC viscosity grade and proportion on the functional properties of co-freeze-dried mannitol-HPMC cushioning excipients for compacted MUPS. Eur. J. Pharm. Biopharm. 2020, 151, 98-107. [CrossRef]

82. Zhang, X.; Li, Y.; Huang, Z.; Cui, Y.; Zhao, Z.; Yue, X.; Wang, G.; Liang, R.; Huang, Y.; Tan, W.; et al. Development and pharmacokinetics evaluation of quetiapine fumarate sustained-release tablets based on hydrophilic matrix. J. Drug Deliv. Sci. Technol. 2019, 54, 101322. [CrossRef]

83. Liu, S.; Jing, Y.; Zhang, T.; Zhang, J.; Xu, F.; Song, Q.; Ye, Q.; Liu, S.; Liu, W. Excellent tribological and anti-corrosion performances enabled by novel hollow graphite carbon nanosphere with controlled release of corrosion inhibitor. Chem. Eng. J. 2021, 412, 128648. Available online: https://www.sciencedirect.com/science/article/pii/S1385894721002461 (accessed on 5 May 2021). [CrossRef]

84. Geethamani, P. Corrosion Inhibitors; IntechOpen: London, UK, 2019.

85. Rajakumari, R.; Volova, T.; Oluwafemi, O.S.; Thomas, S.; Kalarikkal, N. Transformation of essential minerals into tablet formulation with enhanced stability. Adv. Powder Technol. 2020, 31, 2806-2819. [CrossRef]

86. Chang, S.-Y.; Sun, C.C. Interfacial bonding in formulated bilayer tablets. Eur. J. Pharm. Biopharm. 2020, 147, 69-75. [CrossRef]

87. Zafari, S.; Shahrak, M.N.; Ghahramaninezhad, M. New MOF-Based Corrosion Inhibitor for Carbon Steel in Acidic Media. Met. Mater. Int. 2020, 26, 25-38. [CrossRef]

88. Popoola, L.T. Organic green corrosion inhibitors (OGCIs): A critical review. Corros. Rev. 2019, 37, 71-102. [CrossRef] 